\title{
The Potential of International Large-Scale Assessments for Meta-Analyses in Education
}

\author{
Ronny Scherer ${ }^{1}$, Fazilat Siddiq ${ }^{2}$, and Trude Nilsen ${ }^{3}$ \\ ${ }^{1}$ Centre for Educational Measurement at the University of Oslo (CEMO), Faculty of Educational \\ Sciences, University of Oslo \\ ${ }^{2}$ University of South-Eastern Norway, Department of Education and Quality in Learning, Unit \\ for Digitalisation and Education \\ ${ }^{3}$ University of Oslo, Faculty of Educational Sciences, Department of Teacher Education and \\ School Research
}

\section{Author Note}

Ronny Scherer (ib https://orcid.org/0000-0003-3630-0710

Fazilat Siddiq (ib https://orcid.org/0000-0003-3811-6124

Trude Nilsen (ib https://orcid.org/0000-0003-1640-4598

We have no known conflict of interest to disclose. This research was supported in part by a grant from the Research Council of Norway (NFR-FINNUT Grant 254744 “Adapt21”). The supplementary material can be accessed via https://doi.org/10.17605/OSF.IO/NT5QJ.

Correspondence concerning this article should be addressed to Ronny Scherer, Centre for Educational Measurement at the University of Oslo (CEMO), Faculty of Educational Sciences, University of Oslo, Postbox 1161 Blindern, NO-0318 Oslo. Email: ronny.scherer@cemo.uio.no

This preprint has been submitted for peer review. SUBMISSION DATE: 23 March 2021. 


\begin{abstract}
Meta-analyses and international large-scale assessments (ILSA) are key sources for informing educational policy, research, and practice. While many critical research questions could be addressed by drawing evidence from both of these sources, meta-analysts seldom integrate ILSAs, and the current integration practices lack methodological guidance. The aim of this methodological review is therefore to synthesize and illustrate the principles and practices of including ILSA data in meta-analyses. Specifically, we (a) review systematically whether and how existing meta-analyses included ILSA data; (b) present four inclusion approaches (i.e., analytic steps, potential, challenges); and (c) illustrate the application of these approaches. Seeing the need for meta-analyses on educational inequalities, we situated the review and illustration in the context of gender differences and socioeconomic gaps in student achievement. Ultimately, we propose an analytic framework outlining the steps meta-analysts could take to utilize the potential and address the challenges of ILSA data for meta-analyses in education. Keywords: Gender differences; Digital literacy; International large-scale assessments; Meta-analysis; Socioeconomic status
\end{abstract}




\section{The Potential of International Large-Scale Assessments for Meta-Analyses in Education}

Evidence-based decision-making is key to educational policy and practice. To facilitate this, researchers synthesize the body of evidence on, for instance, the effectiveness of educational programs, the factors related to desirable educational outcomes, and possible sources of variation or inequalities in education via meta-analyses (Hattie et al., 2014; Oh, 2020). These quantitative research syntheses must provide reliable, meaningful, and unbiased evidence so that valid inferences can be drawn by researchers, practitioners, and policy-makers (Slavin, 2008). However, meta-analyses in education and other disciplines face several challenges compromising their validity (e.g., Ahn et al., 2012; Rios et al., 2020; Sharpe, 1997): smallsample primary studies (e.g., low power to detect practically relevant effect sizes, high uncertainty, risk of invalid generalizations to student populations), study characteristics that may affect the quality and magnitude of effects (e.g., convenience samples, lack of stratification, matching, or control groups), and insufficient psychometric quality of the outcome measures (e.g., low reliability, limited construct coverage) — just to name a few. International large-scale assessments (ILSAs), such as ICILS (International Computer and Information Literacy Study), TIMSS (Trends in International Mathematics and Science Study), and PISA (Programme for International Student Assessment), address many of the issues meta-analyses face and have similar purposes as meta-analyses (Braun \& Singer, 2019; Wagemaker, 2016). Specifically, ILSAs include large and representative samples, follow multi-stage and randomized sampling designs, and provide outcome measures fulfilling high-quality psychometric standards (Klieme, 2020; Rutkowski et al., 2010). Despite this potential, it is not a common practice to include ILSA data in meta-analyses on key educational research questions per se. For instance, in their metaanalysis of the relation between socioeconomic status and student achievement, Kim et al. (2019) 
and Scherer and Siddiq (2019) included ILSA and non-ILSA data side-by-side, while Sirin (2005) and Harwell et al. (2017) based their meta-analyses solely on non-ILSA data, although ILSA data would have been eligible for inclusion. Similarly, some meta-analyses of the gender differences in student achievement included both ILSA and non-ILSA data (Lietz, 2006; Siddiq \& Scherer, 2019), while some focused on only non-ILSA (Lindberg et al., 2010) or ILSA data (Else-Quest et al., 2010). Part of the reasoning behind these varying practices may lie in the complexities of the primary ILSA and the resultant meta-analytic data. These complexities include the multi-stage sampling designs that need to be represented in the estimation of effect sizes, the availability of multiple effect sizes per ILSA or country, the risk of bias in the metaanalytic statistics due to the dominance of large-scale data, and the lack of analytic approaches guiding the integration of ILSA in meta-analyses (e.g., Hedges, 2007; Rutkowski et al., 2010).

Overall, the inclusion of ILSA data in meta-analyses has faced two key challenges: Varying inclusion practices, likely due the lack of methodological guidance, and the complex ILSA designs and meta-analytic data structures that demand non-standard effect size computation and advanced meta-analyses. Our methodological review addresses these challenges by (a) reviewing systematically whether and how existing meta-analyses included ILSA data; (b) presenting an analytic framework that comprises four inclusion approaches; and (c) illustrating these approaches. We offer specific recommendations for researchers on how to include ILSA data in their meta-analyses to inform evidence-based practice and policy-making.

For educational policy, one of the critical topics in need of ongoing meta-analyses is that of educational inequality (Berkowitz et al., 2017; Broer et al., 2019). Providing students with equal opportunities and access to education is key to the sustainable development of societies, and has thus become a top priority within education (OECD \& netFWD, 2019). Within 
educational inequality, gender differences and gaps between students of different socioeconomic in educational achievement are prominent indicators of such inequalities (UNESCO UIS, 2018). Our methodological review consequently situates the review of the inclusion practices in the context of educational inequality and focuses on meta-analyses of the gender differences and socioeconomic status (SES) gaps in student achievement. Besides, we illustrate the inclusion approaches for a meta-analysis of the gender differences in digital literacy.

International Large-Scale Assessments (ILSAs) and Meta-Analyses in Education Potential of ILSAs for Informing Educational Research, Practice, and Policy-Making Purposes and Contribution

Meta-analyses and ILSAs have similar purposes. Oh (2020) identified three evidencebased uses of meta-analyses: (a) Informing the design of empirical studies; (b) informing the interpretation of the effect sizes resulting from primary studies by creating context and providing benchmarks; (c) informing educational practice and the development of professional guidelines for research. Besides, meta-analyses have several theoretical uses, such as providing information about population effect sizes, quantifying heterogeneity, and identifying the extent to which sample, study, and measurement characteristics could explain this heterogeneity (Borenstein et al., 2009). Ultimately, meta-analyses are aimed at supporting research, practice, and policy in drawing robust conclusions about key educational issues and explaining how and why specific findings may fit together or deviate (Glass, 1976; Siddaway et al., 2019). 
Similarly, ILSAs provide large-scale, representative, and international data to (a) increase the understanding of key factors influencing teaching and learning, including contextual factors; (b) identify key educational issues; (c) inform national strategies for monitoring and improvement, including evaluating the effectiveness of curricula, instruction, and policies; (d) contribute to the research community to facilitate educational evaluation and document progress in research; (e) create de facto benchmarking, providing context for small-scale research and tracing student achievement across nations and over time (Braun \& Singer, 2019; Hopfenbeck et al., 2018; Wagemaker, 2016). The next sections demonstrate that ILSAs have a value in their own right for meta-analyses in education and how they may address some of the challenges meta-analyses are facing.

\section{Key Educational Issues and Constructs}

ILSAs contain rich indicators of educational achievement, oftentimes in several domains and sub-domains, motivational and affective constructs, background characteristics, and contextual factors, which are measured across the different levels of educational systems and over time. These indicators are documented transparently and allow researchers to assess and monitor key educational issues, such as equity and equality, trends and profiles of student achievement, and the link between school practices and educational outcomes (e.g., Klieme, 2020; Lenkeit et al., 2015). Although ILSAs keep most of these indicators or topics constant over time (to ensure the monitoring of trends), they also include additional indicators or topics to address important societal changes and new research foci (Strietholt \& Scherer, 2018). The assessment of key constructs in countries that participated in multiple ILSA cycles provides a unique opportunity for longitudinal analyses and for identifying possible trends over time at the country or system level (e.g., Ertl et al., 2020). 


\section{Rigorous Study Designs and Quality Assurance}

ILSAs follow a rigorous design with multiple stages of quality assurance before, during, and after the assessments (Musu et al., 2020; Wagemaker, 2020). Ultimately, these stages are aimed at reducing the possible sources of bias (e.g., through representative, multi-stage random, and large-scale samples), and achieve a sufficient degree of comparability across the participating countries. Klieme (2020), for instance, noted the high-quality standards of coding, sampling, and scaling and highlighted their value for educational effectiveness research. These standards, the underlying procedures, and the quality of the data may qualify ILSAs for many meta-analyses in education. Besides, large ILSA samples increase the precision of the effect size estimates, can improve the generalizability of the effects (Ahn et al., 2012), and thus overcome the challenges associated with small-sample studies in meta-analyses (Pigott \& Polanin, 2020).

\section{Reducing the Risk of Cultural and Language Bias in Meta-Analyses}

Given that ILSAs include a broad range of countries, cultures, and educational systems, including ILSA data in meta-analyses can balance the representation of cultural and language groups - in fact, possible cultural and language bias may be reduced in meta-analyses (Morrison et al., 2012). While meta-analysts oftentimes exclude studies and reports that were not published in English, the information on the various ILSA samples, assessments, and results are made available in English, irrespective of the language of origin in the countries. For instance, examining the relation between socioeconomic status and student achievement in their metaanalysis, Kim et al. (2019) included multiple samples from different ILSAs to quantify this relation for a range of developing countries. In their meta-analysis of the relation between academic achievement and self-concept, Möller et al. (2020) included multiple PISA samples from around the world - cultural balance was of particular importance in their meta-analysis due 
to the substantial cultural differences in self-concept. ILSA data enabled the authors to achieve this balance. However, population heterogeneity in the measurement of constructs can be problematic in the analysis of the primary ILSA data, because deficits in invariance may undermine claims of comparability (Rutkowski et al., 2019).

\section{Data Availability and Comparability}

Finally, we would like to highlight the availability of the primary data along with rich documentation as another strength of ILSAs - specifically, for the most part, ILSA data are freely available to meta-analysts through open-access platforms of the respective organizations (primarily the IEA and OECD). Given this availability, meta-analysts may not have to rely on the reporting from secondary sources, but can extract or estimate the relevant effect sizes themselves. For instance, if researchers are interested in the achievement differences between private and public schools after controlling for schools' socioeconomic composition and individual differences in socioeconomic status, they can specify and estimate a multilevel regression model with the variables of interest, utilizing multiple ILSA data sets. Across these data sets, the model generating the effect sizes is the same, and comparability of the type of effects is given. However, if the researchers extracted the achievement differences from secondary reports which were based on different multilevel regression models (e.g., with different predictors), the resultant effect sizes would no longer be comparable, and the validity of the meta-analytic results would be in question (Becker $\& \mathrm{Wu}, 2007$ ) — this is a key issue in metaanalyses that are based on regression models (e.g., Polanin et al., 2020). In this sense, ILSA data allow meta-analysts to control the specification and estimation of the statistical models used to generate the effect sizes (Cheung \& Jak, 2016). 
Besides the comparability of the statistical models, many ILSAs, ILSA cycles, and samples are based on the same or linked measures of constructs. However, although this design ensures some degree of comparability or, more precisely, a similar exposure to items and tasks, it does not ensure measurement invariance per se. Researchers and large-scale data analysts still have to provide evidence that the measurement models representing specific constructs are sufficiently invariant - nonetheless, if this condition holds, possible bias due to the differential functioning of measures, tasks, or items can be reduced and, thus the comparability of effect sizes improved (van de Vijver et al., 2019).

\section{Conclusion}

Overall, ILSAs represent rich and open data sources for educational researchers to explore the levels of and relations among constructs, report relevant group differences in educational outcomes and processes, and monitor them over time and across countries. With their rigorous designs and measures, ILSAs further represent high-quality primary studies metaanalysts may consider for inclusion in meta-analyses, given that they fit to the specific research questions, contain the relevant constructs and effect sizes, and fulfill all other inclusion criteria. Including ILSAs in meta-analyses can offer extended opportunities to compare the effect sizes of interest across study, sample, and measurement characteristics.

\section{Challenges of Including ILSA Data in Meta-Analyses in Education}

Despite the potential that lies within ILSA data, including these data in meta-analyses poses several challenges. In the following, we highlight these challenges.

\section{Selection of Constructs}

Although ILSAs contain a rich set of constructs and indicators, the feasibility and time constraints in which they operate allow for including only a selection of constructs, types of 
tasks, and scales (Gustafsson, 2018; Kuger \& Klieme, 2016). These constraints stimulated the development of innovative assessment designs, including multi-matrix and multi-stage testing (Yamamoto et al., 2018), to cover a broader set of constructs and, at the same time, not overburden test takers. Along with these efforts, the range of constructs, especially on the student achievement side, has been extended from the traditional domains of mathematics, science, and reading to cross-curricular skills, such as problem solving, global competence, and digital skills (Strietholt \& Scherer, 2018). Despite these efforts, meta-analysts may still find that ILSA data do not contain the information on key constructs suitable for their research syntheses - as with any other data source. This lack could either be due to construct under-representation or the lack of construct measurements. For instance, personality, general cognitive abilities, or socio-emotional skills have not been covered by ILSAs to a large extent. To this end, ILSA data still have to undergo the screening for relevant constructs, and meta-analysts may find that ILSA data are not eligible after all. Besides, in specific contexts, some ILSAs may be better suitable than others. For instance, addressing research questions on the contextual classroom and teacher effects may exclude most PISA data (only student- and school-level variables available), yet include TIMSS and PIRLS data (student-, classroom-, teacher-, and school-level variables available).

\section{Correlational Nature of the Data}

The correlational nature of the ILSA data, resulting from the cross-sectional study design, may be another issue that could exclude these data from meta-analyses in education, especially when effectiveness questions are addressed that require (quasi-)experimental designs (Klieme, 2013). In fact, ILSAs offer only limited opportunities to draw causal inferences (Rutkowski \& Delandshere, 2016), and may inform meta-analysis primarily by group differences (e.g., gender differences in student achievement) or relations among constructs (e.g., relation between self- 
concept and student achievement). For instance, research questions on the effectiveness of instruction can hardly be addressed directly, and randomized-controlled trials would obviously be the gold standard to inform such questions. Given their design, ILSA data would not be eligible for inclusion in meta-analyses of the effectiveness of instruction. Yet, ILSAs could still provide information about the distribution of relevant variables and their relations to educational achievement reported (Braun \& Singer, 2019; Klieme, 2020).

\section{Complex Survey Designs and Large Samples}

Another challenge associated with the use of ILSA data in meta-analysis is the extraction of the correct effect sizes. ILSA data follow a complex survey design with multiple stages of sampling that require advanced methods to estimate effects (Rust, 2014) — among others, the key elements include the multilevel data structure (e.g., students hierarchically nested in schools), the use of sampling weights (e.g., student- and school-level weights), the correct variance estimation (e.g., via jackknifing techniques and replicate weights), and the achievement estimation (e.g., via plausible value techniques). For instance, if meta-analysts are interested in the relation between measures of instructional quality in classrooms and student achievement, multilevel modeling is required to account for the nested structure of the primary ILSA data ("primary clustering") and obtain the contextual effect. While these elements have been discussed and presented in the extant literature extensively (Rutkowski et al., 2010), we suspect that addressing them to extract the relevant effect sizes from secondary data analyses can pose barriers for meta-analysts. Associated with the complex survey design are the large sample sizes within ILSA data. Largesample studies may well increase precision and reduce sampling error, yet may also influence the effect size estimate and its variance components substantially due to large weights in the metaanalytic data set (Turner et al., 2013). 


\section{Complex Meta-Analytic Data Structures}

Besides the primary clustering of the ILSA data, including them in meta-analyses can create a nested structure of the meta-analytic data ("secondary clustering"), with multiple effect sizes extracted from the ILSAs, ILSA cycles, or countries (e.g., Pigott \& Polanin, 2020). Such structures can violate the independence assumption in meta-analysis and require meta-analysts to address them, for instance, via multilevel meta-analysis, robust variance estimation, or pooling approaches (Cheung, 2019; Pustejovsky \& Tipton, 2021; Scammacca et al., 2014). Notice that the primary clustering represents a different analytic problem than the secondary clustering: While the former describes the structure of the primary study data with, for instance, students nested in classrooms, the latter describes the structure of the meta-analytic data with multiple effect sizes nested in, for instance, ILSAs. Addressing the secondary clustering still requires from meta-analysts the knowledge and skills to engage in advanced meta-analytic techniques.

\section{Conclusion}

Overall, the main challenges associated with including ILSA data in meta-analyses relate to their complex design, the complex nature of the meta-analytic data, and the limitations in construct coverage and types of inferences. One may therefore argue that considering only nonILSA data represents a viable solution. However, including only non-ILSA data to address research questions in meta-analyses for which ILSA data may be eligible creates perhaps more severe problems (e.g., low statistical power and precision, publication and language bias; Ertl et al., 2020) and limits the level of generalizability (Ahn et al., 2012).

\section{The Present Study}

As mentioned earlier, both meta-analyses and ILSAs play key roles in education to inform policy, research, and practice. However, although ILSAs may fulfill the eligibility criteria 
in existing meta-analyses, as they follow rigorous sampling designs, include representative samples, and measure key constructs, their inclusion varies substantially. While some metaanalyses did not include any ILSA data (e.g., Harwell et al., 2017; Lindberg et al., 2010), others included publications of secondary ILSA data analyses (e.g., Kim et al., 2019; Scherer \& Siddiq, 2019), or were based only on ILSA data (e.g., Else-Quest et al., 2010; Gray et al., 2019). These inclusion approaches have their strengths and weaknesses, and researchers must be aware of the potential and the limitations of the meta-analytic inferences drawn from them. As we argued earlier, meta-analyses that are based either on ILSA or non-ILSA data, excluding one or the other, risk to introduce different forms of bias and may therefore provide weak evidence.

Given the diversity of the ways in which meta-analysts include or ignore ILSA data and, at the same time, the current lack of guidelines informing this inclusion, the present study reviews and illustrates the principles and practices of including ILSA data in meta-analyses. Specifically, we review the approaches to integrating ILSA data in meta-analyses alongside nonILSA data, addressing the following three general research questions:

1. To what extent have ILSA data been included in existing meta-analyses in education, and how? (Inclusion status)

2. Which analytic approaches can meta-analysts take to include ILSA alongside nonILSA data in their meta-analyses? (Inclusion approaches)

3. How can the different inclusion approaches be implemented in meta-analyses, and what are their advantages and disadvantages? (Inclusion implementation) However, given the unmanageably large body of meta-analyses in education (Ahn et al., 2012), and given the need for meta-analyses of issues related to inequality in education (Broer et al., 2019), we constrained research questions 1 and 3 to specific contexts: First, we illustrate the 
status and practices of including ILSA data via two critical reviews of existing meta-analyses, each of which focus on inequality issues. These issues refer to: (a) Gender differences in student achievement, and (b) the relation between socioeconomic background and student achievement. Second, we describe four analytic approaches to including ILSA data in meta-analyses, discussing their advantages and challenges, alongside the respective methodological complexities. Third, we illustrate the application of these approaches by updating and extending a meta-analysis of the gender differences in digital literacy. Ultimately, the present study results in an analytic framework guiding researchers' on the ways to include ILSAs in meta-analyses.

\section{The Status of Including ILSA Data in Meta-Analyses of Gender Differences and SES}

\section{Gaps in Student Achievement}

\section{Substantive Background}

Educational research has long been concerned with examining and ultimately reducing gaps in educational outcomes between groups of students. Much of the discussion has centered around the contexts of equity and equality in general (Espinoza, 2007), and the gender and socioeconomic status differences in particular (Berkowitz et al., 2017; Else-Quest et al., 2010). In fact, a plethora of primary studies and secondary analyses of ILSA data exists reporting on several indicators of equity and equality both nationally and internationally - the set of indicators includes but is not limited to the variation of students' achievement within and between schools, differences in student achievement between subgroups of students (e.g., gender), relations between measures of socioeconomic status and student achievement, and mediation or moderation effects of contextual variables (e.g., school climate, instructional quality) on these relations (Broer et al., 2019; Gustafsson et al., 2018; Nilsen et al., 2016). Among others, these indicators have become an integral part of the ILSA reporting and existing meta-analyses 
(OECD, 2016; UNESCO UIS, 2018). For instance, describing the SES-achievement relation in the domain of reading, PISA 2018 identified substantial variation in this relation across more than 70 educational systems (OECD, 2019). This ILSA also revealed cross-country variation in the gender gaps in reading achievement, yet with girls consistently outperforming boys. Similarly, other PISA cycles and ILSAs have mapped such gaps in student achievement across educational systems, age groups, subject domains, and over time and thus provide a rich data source for exploring their effect sizes, heterogeneity, and possible explanatory mechanisms (Broer et al., 2019; Gray et al., 2019). The latter represent key elements of existing metaanalyses in this area: For instance, in their seminal meta-analysis of the SES-achievement relation based on non-ILSA data, Sirin (2005) found moderate and positive correlations with substantial between-study heterogeneity and discovered moderator effects of measurement and sample characteristics. Despite focusing only on teacher-assigned grades as measures of student achievement, Voyer and Voyer (2014) identified small but significant gender differences in achievement favoring girls, along with between-study heterogeneity, and moderator effects. These examples of ILSAs and meta-analyses exemplify their goals of quantifying and explaining possible achievement gaps in education.

To examine the extent to which ILSA data have been utilized to inform the meta-analytic body of knowledge and which approaches to including these data meta-analysts have taken, we systematically reviewed existing meta-analyses of the gender differences and SES gaps in student achievement. As noted earlier, we constrained this review to the contexts of gender differences and SES gaps, two key issues in education. In this sense, the following two systematic reviews showcase the status of inclusion and inclusion approaches. 


\section{Methods}

We used the systematic review methodology to identify the relevant studies within the scope of this paper, and followed the recommended steps, including predefining research questions, development of the search strategy, defining inclusion and exclusion criteria, screening, data extraction, appraisal, and synthesis (Higgins et al., 2019). In the following sections, we describe the application of these steps.

\section{Search Strategy}

To retrieve the relevant meta-analyses, we developed a search strategy by first identifying the key terms for answering the aims of this study and identified the most commonly used synonymous for each term. We then performed two independent searches in the databases ERIC (Education Resources Information Center) and PsycINFO, combining search terms related to (a) the study design: meta-analysis or meta-analytic; (b) the outcome variable: achievement or performance or literacy or numeracy or reading or math* or science; and (c) the independent variable. For the latter, we used the search terms "gender difference* or sex difference* or gender gap" for meta-analyses of gender differences and "SES or socioeconomic status or socioeconomic status or number of books or parent* education or parent* occupation or income or ESCS or HISEI or ISEI or possession* or capital” for meta-analyses reporting the relation between SES and student achievement. We extended these searches by hand-searching publications in key journals in the field (Educational Research Review, Review of Educational Research, Psychological Bulletin, Journal of Educational Psychology, Large-scale Assessments in Education) and the database PsyArXiv to identify possible preprint publications eligible for inclusion. Supplemental material S6 contains the full search strategies, including the specific 
search terms. After removing duplicates, these searches yielded 318 publications for the gender meta-analyses and 271 publications for the SES meta-analyses (see Figure 1).

\section{Screening and Coding}

The retrieved publications were then screened in two steps: First, we reviewed the abstracts for their topic fit, considering meta-analyses that were published in English between 1995 and 2020. Besides, the full texts of these publications must have been made available, the topic must have related to the designated content areas (i.e., gender differences in student achievement or relations between SES and student achievement), and the authors must have performed a meta-analysis - theoretical reviews, comments, methodological papers, and errata were excluded. This first step resulted in 19 published meta-analyses eligible for further screening for the gender meta-analyses and 36 publications for the SES meta-analyses (see Figure 1). Second, we reviewed the full texts according to the following criteria:

- Type of research question and data: The research question concerning gender differences in student achievement or the relation to SES are of correlational nature, and the data were observational. Exclude: Meta-analyses on the effectiveness of interventions.

- Sample: ILSAs contain the student samples the meta-analyses focused on. Exclude: Meta-analyses focusing on children younger than primary school students, children with medical conditions or disorders, and children that were selected according to some criterion that could not be found in ILSAs (e.g., executive function scores).

- Content and constructs: The constructs and contents of the meta-analyses were included in ILSAs. Exclude: Meta-analyses utilizing achievement or SES measures that were not assessed in ILSAs (e.g., working memory measures, school grades, parents' income). 
- Direct relations: Direct relations between the constructs (i.e., gender or SES and student achievement) were reported. Exclude: Meta-analyses that use the key constructs as moderators (e.g., Peng et al., 2019).

- Reported statistics: Independent of their inclusion, ILSA data could provide the statistics and effect sizes needed for the meta-analysis.

- Inclusion criteria: Irrespective of their inclusion, ILSA studies fulfilled the inclusion criteria of the meta-analysis (i.e., would be eligible for inclusion). Exclude: Metaanalyses that focused on national large-scale assessments (e.g., Petersen, 2018).

These screening steps yielded eight gender meta-analyses and ten SES meta-analyses which set their inclusion and exclusion criteria so that ILSA studies had been eligible for inclusion (Figure 1). A flowchart describing the screening decisions is shown in Supplementary Material S6.

The coding of these meta-analyses included key characteristics of the studies (i.e., publication year and status, number of studies and effect sizes, context), the measures (i.e., achievement domain, SES dimension(s), SES source(s), SES metric), the meta-analytic models (i.e., type of model(s), addressing the dependence structure, pooled effect size(s)), and the extent to which ILSA data were included (i.e., inclusion of ILSA data [yes/no], data sources, type(s) of ILSAs, cycle(s), inclusion approach, sensitivity analyses). Supplementary materials S1 and S2 contain the detailed coding of the gender and SES meta-analyses.

\section{Results}

\section{Meta-Analyses of Gender Differences in Student Achievement}

Overall, the $m=8$ meta-analyses examining gender differences in student achievement included 448 studies, oftentimes operationalized as independent study samples, and yielded 6428 effect sizes in total (see Table 1). These meta-analyses covered the domains of reading $(m=5)$, 
mathematics $(m=6)$, science $(m=3)$, and digital literacy $(m=1)$. One meta-analysis was based only on non-ILSA primary studies to avoid redundancies with other meta-analyses (Lindberg et al., 2010), four only on ILSA data (Baye \& Monseur, 2016; Else-Quest et al., 2010; Gray et al., 2019; Keller et al., 2020), and the remaining two meta-analyses included both ILSA and nonILSA data (Lietz, 2006; Siddiq \& Scherer, 2019). To a large extent, PISA and TIMSS data were included in the six meta-analyses that extracted information from ILSA data, followed by PIRLS, SACMEQ, and ICILS data. The two meta-analyses that included ILSA and non-ILSA data side-by-side took a one-stage direct inclusion approach, that is, the authors considered the participating countries and/or ILSAs to be studies yielding multiple effect sizes. None of these meta-analyses considered meta-analytic models with dependency structures — in fact, only one of the eight meta-analyses addressed such structures explicitly via multilevel meta-analysis (Keller et al., 2020). Only Siddiq and Scherer (2019) performed sensitivity analyses comparing the onestage inclusion approach with a two-stage inclusion approach. The latter was based on two steps of meta-analysis: First, ILSA data were meta-analyzed, and the resultant weighted average effect size was extracted as a representative of the effects from ILSA studies. Second, this effect size was combined with the non-ILSA data and then meta-analyzed. Finally, the gender metaanalyses reported mainly standardized mean differences as effect sizes $(m=7)$, along with variance ratios $(m=2)$. In sum, six of the eight meta-analyses utilized ILSA data, only two of which directly included ILSA and non-ILSA data.

\section{Meta-Analyses of the Relation Between SES and Student Achievement}

The sample of $m=10$ meta-analyses describing the relation between SES and student achievement yielded 1631 effect sizes based on 556 studies (see Table 2). These effect sizes were mainly reported as correlations $(m=9)$ and in only one meta-analysis as a standardized 
mean difference. The meta-analyses covered a broad range of achievement domains, including literacy $(m=7)$, mathematics $(m=6)$, science $(m=6)$, general cognitive skills $(m=6)$, social sciences $(m=1)$, and digital literacy $(m=1)$, some of which were assessed not only by achievement tests but also school grades. The SES measures covered multiple dimensions, including parents' income, occupation, and education, in all meta-analyses. Four meta-analyses were based on non-ILSA data and did not provide any reason for this exclusion (Harwell et al., 2017; Letourneau et al., 2013; Rodríguez-Hernández et al., 2020; Sirin, 2005), while six included both ILSA and non-ILSA data (Kim et al., 2019; Liu et al., 2020; Scherer \& Siddiq, 2019; Tan, 2017; Tan et al., 2019; van Ewijk \& Sleegers, 2010). None of the meta-analyses were based only on ILSA data. Primarily, the meta-analysts chose the PISA, TIMSS, ICILS, and SACMEQ data to inform their meta-analyses and consistently took a one-stage direct inclusion approach, considering the countries or ILSA cycles as separate studies. Two meta-analyses reported sensitivity analyses: Scherer and Siddiq (2019) compared the one-stage direct inclusion with the two-stage direct inclusion and examined the effects of excluding ILSA data; van Ewijk and Sleegers (2010) also examined the effects of excluding ILSA data. Accounting for the dependencies among multiple effect sizes per study, Liu et al. (2020) performed robust variance estimation, Scherer and Siddiq (2019) conducted three-level meta-analysis, and van Ewijk and Sleegers (2010) modified the weights in a meta-regression model similar to the robust variance estimation. In sum, six of the ten SES meta-analyses included ILSA data next to non-ILSA data utilizing mainly the one-stage direct inclusion.

\section{Summary of Key Findings}

Our systematic review of meta-analyses on gender differences in student achievement and the relation between SES and achievement indicated that (a) ILSA data were not eligible for 
all meta-analyses on these topics, for instance, due to misfit of the target samples, types of achievement measures, or the focus on national rather than international assessment data; (b) several meta-analyses included ILSA data, yet to different degrees (i.e., ILSA data only, ILSA and non-ILSA data side-by-side); (c) meta-analysts primarily took a one-stage direct inclusion approach and hardly considered alternative approaches and sensitivity analyses; (d) the structure of the meta-analytic data sets with multiple effect sizes per study was hardly considered.

\section{Review and Illustration of the Approaches to Including ILSA Data in Meta-Analyses}

\section{Analytic Framework of the Inclusion Approaches}

The meta-analytic literature on multilevel meta-analysis (Fernández-Castilla et al., 2020), meta-analysis with individual participant data (Burke et al., 2017), and Bayesian meta-analysis (Röver, 2020) offers a plethora of approaches to synthesize effect sizes from small- and largescale studies, with or without complex data structures, including one- and two-stage procedures. On the basis of these approaches and the knowledge gained from the systematic reviews addressing our first research question, we propose an analytic framework that contains four approaches to include ILSA data in existing meta-analyses at the level of effect sizes:

1. Separate meta-analyses: ILSA and non-ILSA data are meta-analyzed separately.

2. Indirect inclusion via Bayesian meta-analysis: In a first step, the multiple effect sizes per ILSA are meta-analyzed, yielding estimates of the weighted average effect size $(\overline{E S})$ and the respective heterogeneity $\left(\tau^{2}\right)$. In a second step, one or more of these estimates inform the prior distribution of the weighted average effect size and the heterogeneity for the non-ILSA data. 
3. One-stage direct inclusion: ILSA and non-ILSA data (i.e., effect sizes) are included in a meta-analysis side-by-side and at the level of the effect sizes. For ILSA data, multiple effect sizes (e.g., for multiple countries or domains) are extracted.

4. Two-stage direct inclusion: In the first stage, the multiple effect sizes per ILSA are meta-analyzed or aggregated following some aggregation rules (e.g., Borenstein et al., 2009). In the second stage, the resultant, aggregated effect size estimates for each ILSA are included in the meta-analysis next to the non-ILSA data.

We review the analytic steps, decisions, advantages, and challenges associated with each of these four approaches (see also Table 3) and illustrate their application.

\section{Effect Size Measures}

The four presented approaches are all based on the assumption that the correct effect sizes have been extracted from the ILSA and the non-ILSA data. In this context, "correct" refers to effect size and sampling variance estimates in which the complex survey design was accounted for, especially the hierarchical structure of the ILSA data (Lai \& Kwok, 2016; Tymms, 2004). For instance, when meta-analysts are interested in deriving the correct effect size measures for gender differences in achievement, the standardized mean difference $(S M D)$ may be the effect size of their choice (Borenstein et al., 2009). When computing $S M D$, the pooled standard deviation can incorporate information about the nesting of the primary study data (e.g., students nested in classrooms or schools). Hedges (2007) proposed several ways to incorporate the intraclass correlation $I C C_{1}$ into the estimate of the pooled standard deviation. While such adjustments of the effect sizes are straightforward, they depend on the authors' reporting of the relevant statistics, especially the intraclass correlation. 
Besides the accounting for the nesting of the primary data, further elements may inform the estimation of the effect sizes, such as the use of sampling weights or performance assessment designs that draw from a set of plausible values (Rutkowski et al., 2010). Given that the raw primary data are oftentimes not available, meta-analysts may have to trust the estimation and reporting of the effect sizes in the publication and have hardly any chance to perform further adjustments. However, such adjustments are possible for most ILSA data — in fact, if the raw data of primary studies are available, the meta-analysts are in full control of the effect size estimation. In such a situation, multilevel modeling, weighting, and plausible-value combination approaches are available to account fully for the complex survey design of ILSAs (Rust, 2014).

Overall, meta-analysts have at least two options to address the complex survey design, especially the nested data structure, in primary studies: (a) Adjust the reported effect sizes via the $I C C_{1}$ (Hedges, 2007); or (b) analyze the raw data (if available) via multilevel modeling (Kim et al., 2012).

\section{Extension of a Meta-Analysis on Gender Differences in Digital Literacy}

In the following, we describe the four inclusion approaches in greater detail and illustrate their application with a meta-analysis on the gender differences in digital literacy.

Supplementary Material S4 and S5 contain the R code, the detailed analytic steps (see also Table 3), and the respective results.

\section{Meta-Analytic Data Set and Aims}

Siddiq's and Scherer's (2019) original meta-analysis contained 23 primary studies yielding 46 standardized mean effect sizes and included the data from ICILS (International Computer and Information Literacy Study) 2013. Updating this open-access data set, we added the recently published data from ICILS 2018 (Fraillon et al., 2020). Ultimately, this data set 
utilized for illustrating the inclusion approaches contained 24 primary studies and 59 effect sizes. Hedges' $g$ represented the standardized mean differences between girls and boys with positive effect sizes indicating higher performance scores for girls. In the original study, the authors aimed to quantify an overall effect size $(\bar{g})$, the between-study heterogeneity $\left(\tau^{2}\right)$, and the moderator effects of, for instance, test fairness $(0=$ test fairness was not examined, $1=$ test fairness was examined $)$ and publication type $(0=$ published, $1=$ grey literature $)$. Illustrating the inclusion approaches, we addressed these aims and further examined whether two country-level variables, Power Distance Index (PDI; see Hofstede, 2001) and the Global Innovation Index were additional moderators (GII; see Cornell University et al., 2020). Supplemental Material S1 contains the data and describes how these variables were derived.

\section{Separate Meta-Analysis}

Analytic approach. Separate meta-analyses of ILSA and non-ILSA data do not directly integrate the two data sources. Ultimately, they result in separate estimates of the weighted average effect sizes and variance components (Table 3), which could inform alternative approaches, such as the two-stage direction and indirect inclusion approaches, or serve the purpose of benchmarking (e.g., ILSA effect sizes as benchmarks for non-ILSA effect sizes, or vice versa). Nevertheless, if the same meta-analytic models are specified for the two data sources, direct comparisons of the overall effect sizes are possible utilizing mixed-effects models and Wald tests even under heteroscedasticity (Rubio-Aparicio et al., 2020). Meta-analysts can examine moderator effects separately and compare the results qualitatively. If comparisons of effect sizes are not the main focus, conducting separate meta-analyses further allows researchers to specify different meta-analytic models for the ILSA and non-ILSA data, addressing their 
individual complexities (e.g., non-nested structure of the non-ILSA data, nested structure of the ILSA data; Table 3).

Results. Performing separate meta-analyses via random-effects modeling, we obtained estimates of the weighted average effect sizes for the ICILS 2013, ICILS 2018, the combined ICILS 2013 and 2018, and the non-ILSA data sets. Table 4 shows these estimates, which ranged between $\bar{g}=0.12$ and 0.21 and exhibited heterogeneity between the samples within these data sets. Notably, the overall effect size of the ICILS 2013 data was comparable to that of the nonILSA data $(z=-0.3, p=.76)$; yet, the ICILS 2018 data showed a significantly higher overall effect $(z=-1.8, p=.07)$. The degree of heterogeneity varied between these data sets (see also Figure 4): While the non-ILSA effect sizes varied substantially $\left(\tau_{(2)}^{2}=0.033, I^{2}=95.4 \%\right)$, the effect sizes for the ICILS 2018 varied less $\left(\tau_{(2)}^{2}=0.012, I^{2}=91.2 \%\right)$, and varied the least for the ICILS 2013 data $\left(\tau_{(2)}^{2}=0.005, I^{2}=78.2 \%\right)$. We extended the random-effects model by adding the variables test fairness, publication status, power distance, and global innovation to the nonILSA data. For the non-ILSA data, publication status negatively moderated the gender differences, with grey literature exhibiting smaller effects, and test fairness positively moderated these differences, with larger effects for studies examining test fairness (Table 5). For the ICILS 2018 and the combined ICILS data, more innovative countries exhibited significantly larger gender effects; this moderation effect was not apparent for ICILS 2013.

\section{Indirect Inclusion via Bayesian Meta-Analysis}

Analytic approach. If the primary interest of the meta-analysts lies in the meta-analysis of non-ILSA data, information from the meta-analysis of ILSA data could be incorporated indirectly via Bayesian meta-analysis. In this approach, the weighted average effect size and/or variance components derived from ILSA data can inform the distributions of the respective 
estimates for non-ILSA data (see Table 3 and Supplementary Material S5). While a general discussion of Bayesian meta-analysis is beyond the scope of this study, one key advantage lies in the possibilities for researchers to incorporate some prior knowledge in their meta-analysis, even when only few effect sizes are available (Röver, 2020). However, specifying informative priors and random-effects models in the Bayesian framework requires some understanding of the possible parameter distributions and may thus not be easily accessible to meta-analysts.

Moreover, the meta-analytic outcomes for the non-ILSA data may depend on the choice of priors, thus necessitating additional sensitivity analyses.

Results. Utilizing the information from the separate meta-analyses, we conducted Bayesian meta-analysis for the non-ILSA data with informative priors on the weighted average effect and the heterogeneity estimates - these priors were based on the effect size and variance estimate of the combined ICILS 2013 and 2018 data (for the detailed specification of the priors, see Supplementary Material S5). The overall effect size was $\bar{g}=0.12$, with a $95 \%$ confidence interval similar to the effect for the non-ILSA data and a between-sample variance of $\tau_{(2)}^{2}=0.036$ (Table 4). Assessing the convergence of the Markov chains and the posterior distributions indicated that stable estimates were obtained. Besides, varying the prior distributions did not show substantial sensitivity of the Bayesian effect size and variance estimates. Similar to the separate meta-analysis of the non-ILSA, the publication status moderated the gender differences in digital literacy; yet not the test fairness (Table 5).

\section{One-Stage Direct Inclusion}

Analytic approach. The one-stage direct inclusion approach combines the ILSA and non-ILSA data directly at the level of effect sizes. For each ILSA study or wave (e.g., PISA 2006, PISA 2015), each country or cohort sample contributes an effect size (see Figure 3a). This 
inclusion is comparable to the one-stage meta-analysis of individual participant data, in which multiple data sets are combined directly (Burke et al., 2017). If meta-analysts allow for including multiple countries or cohort samples, this direct inclusion ultimately results in a complex metaanalytic structure with multiple effect sizes per ILSA. Such a structure violates the basic assumption of the independence of effect sizes, because effect sizes from the same ILSA may be more homogeneous than effect sizes from different ILSAs (Borenstein et al., 2009). As a consequence, meta-analysts must determine the structure of the meta-analytic data set and choose among suitable approaches to estimate the overall effect sizes and/or moderation effects that represent this structure (Cheung, 2019). Figure 2 illustrates two of the possible structures meta-analysts may encounter in this situation: Given the availability of multiple effect sizes per ILSA, the "ideal" structure with one effect size per ILSA only does no longer apply (Figure 2a). Instead, a hierarchical structure with multiple effect sizes nested in ILSAs (Figure 2b) or a nonhierarchical cross-classified structure with multiple effect sizes nested in ILSAs and countries (Figure 2c) may better represent the meta-analytic data. The latter may be especially useful when including multiple ILSAs or ILSA cycles. If however only one ILSA or ILSA cycle is included, the country-specific effect sizes are considered independent, and the non-ILSA data contribute one effect per study, the structure may be simplified to Figure $2 \mathrm{a}$.

Having identified the data structure, meta-analysts can then choose how to handle such dependencies (see Table 3). While the described structures can be modelled explicitly via multilevel meta-analysis, a random-effects modeling approach that quantifies variation at the respective levels of analysis (e.g., within and between studies), or implicitly considered via robust variance estimation (RVE; e.g., Fernández-Castilla et al., 2020; Hedges et al., 2010). Given the variety of approaches to handling multiple effect sizes, meta-analysts may consider 
conducting sensitivity analyses, varying these approaches and examining the possible differences in the resultant estimates (Table 3). Later in the data-analytic process, the possible differences between the effect sizes extracted from ILSA and non-ILSA studies can be examined and the effects of including ILSA data quantified. While the direct inclusion may require advanced metaanalytic models, meta-analysts can obtain information on different variance components, examine moderator effects at different levels of analysis, and gain precision in the effect size and variance estimates due the increased sample size (see Table 3).

Results. Directly combining the effect sizes obtained from ILSA and non-ILSA data resulted in a nested structure with multiple effect sizes per study. We therefore specified a threelevel random-effects model addressing this structure (see Figure 2b) — this model exhibited a significantly better fit to the meta-analytic data than a model ignoring the nesting (see Figure 2a), $\chi^{2}(1)=10.0, p=.002$. Moreover, the three-level model exhibited substantial within-study variation in addition to the between-study variation (see Table 4). The respective overall effect size was $\bar{g}=0.13(95 \% \mathrm{CI}[0.05,0.21])$ and showed significant heterogeneity $\left(Q_{E}[58]=592.5\right.$, $p<.001)$. Adding the potential moderator variables resulted in a significant effect of publication status $(B=-0.21, S E=0.10, p=.04)$ and global innovation $(B=0.01, S E=0.00, p<.001$; see Table 5). Overall, about $46 \%$ of the between-sample and $2 \%$ of the between-study variation could be explained. Moreover, the difference in gender effects between ILSA and non-ILSA data was insignificant $(B=0.05, S E=0.13, p=.72)$. In our example, random-effect models with RVE only identified the moderating effect of the publication type (Supplementary Material S5).

Given that some countries in the samples contributed multiple effect sizes (e.g., to the ICILS 2013, ICILS 2018, and non-ILSA data), an additional level of nesting may exist. To examine the degree of possible between-country variation in the effect sizes, we extended the 
three-level model to a four-level cross-classified random-effects model (see Figure 2c). This model exhibited a better fit than the three-level model $\left(\chi^{2}[1]=4.2, p=.04\right)$ and showed that between-country variation existed, in addition to within- and between-study variation (see Table 4). The corresponding effect size was $\bar{g}=0.10$ (95\% CI $[0.01,0.18])$. Similar to the three-level model, the effects of publication status $(B=-0.21, S E=0.10, p=.04)$ and global innovation existed $(B=0.01, S E=0.00, p<.001$; see Table 5). However, this model showed that most variance could be explained at the country level (49.1\%), yet not the study level $(2.9 \%)$.

\section{Two-Stage Direct Inclusion}

Analytic approach. Unlike the one-stage approach, the two-stage approach handles the multiple effect sizes per ILSA or ILSA cycle by pooling them first and submitting the resultant, pooled effect size and sampling variance to the meta-analysis with non-ILSA data (see Figure 3b). This approach is similar to that two-stage meta-analysis of individual participant data (Burke et al., 2017). To perform the first stage, meta-analysts may rely on, for instance, Borenstein et al.'s (2009) formula to pool the effect sizes (to the average effect size) and the respective sampling variances (to a pooled variance which includes correlations between the effect sizes within a study). Alternatively, the pooled effect size may also be derived via separate metaanalyses for each of the ILSAs or ILSA cycles (see Table 3). This first stage can simplify the meta-analytic data structure in the second stage, because only one effect size per ILSA or ILSA cycle is included - ultimately, this may result in more robust variance estimates (Declercq et al., 2020). At the same time, the first pooling stage discards the within-ILSA variation (e.g., across countries within ILSA cycles; Figure 3b) — an important source of variation and heterogeneity (Van den Noortgate et al., 2013). Moreover, meta-analysts may face the challenge of including effect sizes that are based on very large ILSA samples which ultimately receive larger weights 
(Borenstein et al., 2009). Examining the sensitivity of the meta-analytic results with respect to including such effect sizes and diagnosing influential effect sizes become key steps in this approach (see Table 3; e.g., Scherer \& Siddiq, 2019).

Results. Utilizing the weighted average effect size and variance estimates of the separate meta-analyses, we combined the non-ILSA effect sizes with one overall ICILS 2013 and one overall ICILS 2018 effect size. Estimating the random-effects model without a nested structure, we obtained an overall gender effect of $\bar{g}=0.12$ (95\% CI $[0.05,0.19]$; see Table 4$)$, and the moderation effect of publication status $(B=-0.22, S E=0.09, p=.01$; see Table 5$)$. The effect of test fairness was statistically significant $(B=0.17, S E=0.08, p=.05$; see Table 5$)$. This additional moderation effect suggested that larger effects were exhibited for studies that examined test fairness, after controlling for the interactivity of the assessment tasks and the publication status. Finally, pooling the ILSA effect sizes via Borenstein et al.'s (2009) procedure in the first stage did not show any different results: The weighted average effect size was $\bar{g}=$ $0.12(95 \%$ CI $[0.05,0.19])$, and the two moderator effects persisted (publication status: $B=-$ $0.22, S E=0.08, p=.01$; test fairness: $B=0.17, S E=0.08, p=.05)$. Further analyses neither flagged the large ILSA-data effect sizes as influential (see Supplementary Material S5).

\section{Summary of Key Findings}

Across the direct inclusion approaches, the overall effect sizes were consistently small and positive. All of these approaches revealed the heterogeneity of the gender effects. The crossclassified model represented the data best for the one-stage direct inclusion and highlighted three additional sources of heterogeneity (next to sampling variation): samples within studies, studies, and countries. Next to the consistency of the fixed effects, the moderator effects of publication status were almost identical in direction and magnitude. Some differences however existed for 
test fairness and global innovation: The one-stage inclusion approach identified the GII moderation effect and located it to the country level—-these effects did not exist when synthesizing only the non-ILSA or ICILS 2013 data. The two-stage inclusion approach and the separate meta-analysis of the non-ILSA data further indicated moderation by test fairness.

\section{Discussion}

\section{Including ILSA Data in Meta-Analyses in Education}

Our systematic review of the extent to which ILSA data were included in existing metaanalyses of gender differences or SES gaps in student achievement showed that ILSA data were not eligible for all meta-analyses. This may have been the main reason why their inclusion was limited. Although ILSAs follow rigorous sampling designs, contain representative samples, and adhere to key methodological standards (Klieme, 2020), these quality characteristics do not ensure their eligibility for any meta-analysis in education per se. In fact, the selection of constructs, samples, assessment modes, and participating countries may also be a limiting factor (e.g., Braun \& Singer, 2019; Rutkowski \& Rutkowski, 2016). For instance, the seminal metaanalysis of gender differences in student achievement by Voyer and Voyer (2014) focused solely on teacher-assigned grades as achievement measures and thus excluded ILSA data. Evaluating the eligibility of studies for inclusion also applies to ILSA data, and meta-analysts should carefully evaluate whether the ILSA samples, constructs, and study designs fit to their inclusion criteria and, ultimately, research purposes. Irrespective of the outcome of this evaluation, communicating the reasons for excluding ILSA data should be an integral part of the methodological rigor of meta-analyses in education (Pigott \& Polanin, 2020). Moreover, given our review of the potential and the analytic opportunities associated with the inclusion of ILSA data in meta-analyses, we encourage meta-analysts to consider ILSA data when searching for 
eligible primary studies and effect sizes - in fact, we argue that searching the existing ILSA databases should become part of the meta-analytic standard procedures in education.

One key issue of including ILSA data in meta-analyses lies in the methodological complexities these large-scale data may impose. As we have showcased while presenting the one-stage direct inclusion approach, the meta-analytic structure of the data that include ILSA and non-ILSA effect sizes can become complex, with hierarchical or even cross-classified structures. While modeling such structures may shed light on the possible sources of variation and the level at which moderators operate, the underlying meta-analytic models are advanced (FernándezCastilla et al., 2020) — this may have been one reason why most meta-analysts refrained from addressing such complex data structures in their meta-analyses of the gender differences and SES gaps in student achievement. Our extension of the meta-analysis of the gender differences in digital literacy included two ILSAs and thus required meta-analytic models accounting for the multiple effect sizes per study and country (e.g., Keller et al., 2020). Meta-analysts should be aware which structure their meta-analytic data set including ILSA and non-ILSA data exhibits to obtain accurate estimates of fixed and random effects (Fernández-Castilla et al., 2020). Another complexity is associated with the decision of which type of ILSA data are included, primary or secondary data? Given the availability of most ILSA data, meta-analysts do not need to rely on the results reported in secondary ILSA data analyses, yet can compute the effect sizes themselves. Although appealing, this opportunity requires that meta-analysts must be aware of the methodological complexities of the primary ILSA data and that they can address them analytically (Rutkowski et al., 2010). Hence, we see the need for training meta-analysts in both the analysis of primary ILSA data to derive the correct effect size estimates and the inclusion approaches for meta-analyses. 
Concerning the four inclusion approaches, notably, our illustrative example showed consistently small estimates of the weighted average gender effect size. With the exception of the separate meta-analysis of the ICILS 2018 data, the estimates were comparable and did not lead to another conclusion. Nonetheless, we refrain from generalizing this result — in other context, with other measures and effect size, and for a different set of ILSA or non-ILSA data, the fixed effects may indeed vary considerably, especially when meta-analyzed separately (Gray et al., 2019). At the same time, some specifications within the inclusion approaches were homogeneous. For instance, the overall gender effects were identical for the separate meta-analysis of the non-ILSA data and the indirect inclusion in our study — in fact, both approaches focused on the non-ILSA data and differed only in the extent to which information from the ILSA data was incorporated (e.g., Röver, 2020). Similarly, the different direct inclusion approaches agreed on the size of the fixed effect.

Considering these observations, meta-analysts may well argue that the choice of the specific approaches may not matter for the reporting of the overall effects. However, some of these approaches are more useful than others, especially for quantifying the sources of variation and the moderator effects (Fernández-Castilla et al., 2020). For instance, the separate metaanalyses can inform both the indirect inclusion and the direct inclusion via the two-stage approach. Moreover, meta-analysts can obtain some information about the possible influence some ILSA data may have on the meta-analysis of non-ILSA data (e.g., in our illustrative example, the ICILS 2018 data exhibited the largest effect size, and the ICILS 2013 data the least heterogeneity) — this may further facilitate the benchmarking and interpretation of the non-ILSA data effect sizes (Wagemaker, 2016). If, indeed, meta-analysts focus on non-ILSA data, the indirect inclusion approach can improve the estimates of the heterogeneity estimates by 
incorporating the knowledge about such parameters in ILSAs (Brunner et al., 2018). Situations in which the heterogeneity and possible moderator effects for ILSA and non-ILSA data are the primary interest may be best addressed via the direct inclusion approaches. While both the oneand two-stage direct inclusion can shed light on between-study heterogeneity and moderation by study-level features, only the one-stage approach can further include between-country heterogeneity and country-level moderation effects (see also Cheng et al., 2018). However, if quantifying and explaining variation at these levels is not in the main focus, meta-analysts may consider correcting the meta-analytic estimates (in particular, the variance components and moderator effects) via robust variance estimation (Hedges et al., 2010). Building on the results of our study and the discussion, in the next section, we provide practical recommendations for including ILSA data in meta-analyses.

\section{Recommendations for Meta-Analyses Including ILSA Data}

Our analytic framework contains four inclusion approaches along with specific steps meta-analysts may take to implement them. Each of these steps should be documented, and the analytic decisions within justified (Pigott \& Polanin, 2020). Once the eligible primary studies and ILSA data sets have been identified, we highlight some analytic aspects that are key when meta-analyzing non-ILSA and ILSA data side-by-side:

- Calculate the correct effect sizes from the primary data. As noted earlier, the correct effect size and sampling variance estimates must be derived from both the non-ILSA and ILSA data. For the latter, both adjustments of effect sizes and the re-analysis of the raw data are largely available - the ILSA official reports already contain some effect sizes that are based on the complex survey design (e.g., gender differences, relations between SES and achievement). Meta-analysts should clearly communicate 
the ways in which they derived the effect size measures, their sampling variance, and how they dealt with the complex survey design of ILSAs.

- Indicate the structure of the meta-analytic data. Despite the nested structure of the primary data (e.g., students nested in classrooms or schools), meta-analytic data can also follow complex structures (e.g., multiple effect sizes nested in studies or ILSAs; see Figure 2). To derive overall estimates of a weighted average effect, meta-analytic models that account for this structure are needed (Fernández-Castilla et al., 2020). Meta-analysts should identify the structure of their data and select the respective meta-analytic models (e.g., multilevel meta-analysis, robust variance estimation). Selecting one effect size per ILSA is not recommended.

- Choose an inclusion approach based on the research questions and goals. As we reviewed the inclusion approaches in our framework, we identify both their strengths and weaknesses. Meta-analysts should carefully consider them and decide for an approach in light of their research questions and purposes. For instance, if only smallscale primary studies are in the focus, ILSA data may only inform the meta-analysis via an indirect inclusion approach. If differences between studies with random versus convenience samples are in the focus, both non-ILSA and ILSA data may inform the meta-analysis via a direct inclusion approach.

- Conduct sensitivity analyses. Sensitivity analyses can shed light on the impact the inclusion of ILSA data in the meta-analysis of non-ILSA data may have on the substantive findings and estimates. Moreover, they indicate the robustness of the specific inclusion approach researchers have taken. 
- Report the analytic steps and decisions transparently. We encourage meta-analysts to document each of the analytic steps and decisions and share their analytic code to facilitate transparency and possible updates of their meta-analyses.

\section{Limitations and Future Directions}

The present study has two core limitations: First, the two systematic reviews provide information about the inclusion of ILSA data in meta-analyses for the two selected topics (i.e., gender differences and the relation between SES and achievement). Although these topics concern key issues in education (e.g., OECD, 2016), especially in the context of equity and equality, the respective findings may not be fully generalizable. In this sense, we encourage researchers to consider extending these reviews into other, educationally relevant topics. Second, our study reviewed the advantages and challenges associated with the application of four inclusion approaches, yet did not examine their performance statistically or via simulation studies. Knowledge about their performance, especially the efficiency, bias, and the precision of the meta-analytic estimates, could further guide the decisions for one or the other approach.

\section{Conclusions}

Overall, we argue that ILSA data hold great potential for informing meta-analyses in education, especially due to their rigorous study and sampling designs, the availability of indicators describing educational systems at multiple levels, and their focus on key issues and constructs in education. This potential may not only assist meta-analysts in expanding their data sets and ultimately improve the precision of the meta-analytic estimates, but also reduce possible publication, cultural, and methodological bias. Another key advantage is that the primary ILSA data are almost entirely available to meta-analysts, who can define and implement the analytic models themselves, yielding effect sizes based on complex survey design directly. At the same 
time, including ILSA data requires a careful choice of an appropriate methodological approach and may extend the analytic steps involved in a meta-analysis by further sensitivity and moderator analyses. Moreover, the complex structure of both the primary ILSA and the resultant meta-analytic ILSA and non-ILSA data must be addressed.

Our proposed analytic framework contains four possible inclusion approaches, outlines the steps meta-analysts may take to examine the possible effects of including ILSA data in their meta-analyses, and provides information on their advantages, disadvantages, and fit to the specific research purposes. We believe that this framework informs and stimulates the inclusion of ILSA data in meta-analyses on key issues in education to ultimately improve the quality, precision, and informativeness of research evidence. 


\section{References}

Ahn, S., Ames, A. J., \& Myers, N. D. (2012). A Review of Meta-Analyses in Education: Methodological Strengths and Weaknesses. Review of Educational Research, 82(4), 436476. https://doi.org/10.3102/0034654312458162

Baye, A., \& Monseur, C. (2016). Gender differences in variability and extreme scores in an international context. Large-scale Assessments in Education, 4(1), 1-16. https://doi.org/10.1186/s40536-015-0015-X

Becker, B. J., \& Wu, M.-J. (2007). The Synthesis of Regression Slopes in Meta-Analysis. Statist. Sci., 22(3), 414-429. https://doi.org/10.1214/07-STS243

Berkowitz, R., Moore, H., Astor, R. A., \& Benbenishty, R. (2017). A Research Synthesis of the Associations Between Socioeconomic Background, Inequality, School Climate, and Academic Achievement. Review of Educational Research, 87(2), 425-469. https://doi.org/10.3102/0034654316669821

Borenstein, M., Hedges, L. V., Higgins, J. P. T., \& Rothstein, H. R. (2009). Introduction to MetaAnalysis. John Wiley \& Sons, Ltd.

Braun, H. I., \& Singer, J. D. (2019). Assessment for Monitoring of Education Systems: International Comparisons. The ANNALS of the American Academy of Political and Social Science, 683(1), 75-92. https://doi.org/10.1177/0002716219843804

Broer, M., Bai, Y., \& Fonseca, F. (2019). Socioeconomic Inequality and Educational Outcomes. Springer.

Brunner, M., Keller, U., Wenger, M., Fischbach, A., \& Lüdtke, O. (2018). Between-School Variation in Students' Achievement, Motivation, Affect, and Learning Strategies: Results from 81 Countries for Planning Group-Randomized Trials in Education. Journal of 
Research on Educational Effectiveness, 11(3), 452-478.

\section{https://doi.org/10.1080/19345747.2017.1375584}

Burke, D. L., Ensor, J., \& Riley, R. D. (2017). Meta-analysis using individual participant data: one-stage and two-stage approaches, and why they may differ. Statistics in Medicine, 36(5), 855-875. https://doi.org/10.1002/sim.7141

Cheng, C., Cheung, M. W.-L., \& Wang, H.-y. (2018). Multinational comparison of internet gaming disorder and psychosocial problems versus well-being: Meta-analysis of 20 countries. Computers in Human Behavior, 88, 153-167. https://doi.org/10.1016/j.chb.2018.06.033

Cheung, M. W.-L. (2019). A Guide to Conducting a Meta-Analysis with Non-Independent Effect Sizes. Neuropsychology Review, 29(4), 387-396. https://doi.org/10.1007/s11065-019$\underline{09415-6}$

Cheung, M. W.-L., \& Jak, S. (2016). Analyzing Big Data in Psychology: A Split/Analyze/MetaAnalyze Approach [Methods]. Frontiers in Psychology, 7(738). https://doi.org/10.3389/fpsyg.2016.00738

Cornell University, INSEAD, \& WIPO. (2020). Global Innovation Index 2020: Who will finance innovation? Cornell University, INSEAD, and the World Intellectual Property Organization. https://www.globalinnovationindex.org/Home

Declercq, L., Jamshidi, L., Fernández Castilla, B., Moeyaert, M., Beretvas, S. N., Ferron, J. M., \& Van den Noortgate, W. (2020). Multilevel Meta-Analysis of Individual Participant Data of Single-Case Experimental Designs: One-Stage versus Two-Stage Methods. Multivariate Behavioral Research, 1-20. https://doi.org/10.1080/00273171.2020.1822148 
Else-Quest, N. M., Hyde, J. S., \& Linn, M. C. (2010). Cross-national patterns of gender differences in mathematics: A meta-analysis. Psychological Bulletin, 136(1), 103-127. https://doi.org/10.1037/a0018053

Ertl, B., Hartmann, F. G., \& Heine, J.-H. (2020). Analyzing Large-Scale Studies: Benefits and Challenges [Opinion]. Frontiers in Psychology, 11(3190). https://doi.org/10.3389/fpsyg.2020.577410

Espinoza, O. (2007). Solving the equity-equality conceptual dilemma: a new model for analysis of the educational process. Educational Research, 49(4), 343-363. https://doi.org/10.1080/00131880701717198

Fernández-Castilla, B., Jamshidi, L., Declercq, L., Beretvas, S. N., Onghena, P., \& Van den Noortgate, W. (2020). The application of meta-analytic (multi-level) models with multiple random effects: A systematic review. Behavior Research Methods, 52, 20312052. https://doi.org/10.3758/s13428-020-01373-9

Fraillon, J., Ainley, J., Schulz, W., Friedman, T., \& Duckworth, D. (2020). IEA International Computer and Information Literacy Study 2018 Technical Report. IEA. https://www.iea.nl/sites/default/files/2020-05/ICILS\%202018\%20Technical\%20ReportFINAL_0.pdf

Glass, G. V. (1976). Primary, Secondary, and Meta-Analysis of Research. Educational Researcher, 5(10), 3-8. https://doi.org/10.3102/0013189X005010003

Gray, H., Lyth, A., McKenna, C., Stothard, S., Tymms, P., \& Copping, L. (2019). Sex differences in variability across nations in reading, mathematics and science. Large-scale Assessments in Education, 7(1), 1-29. https://doi.org/10.1186/s40536-019-0070-9 
Gustafsson, J.-E. (2018). International Large Scale Assessments: Current Status and Ways Forward. Scandinavian Journal of Educational Research, 62(3), 328-332. https://doi.org/10.1080/00313831.2018.1443573

Gustafsson, J.-E., Nilsen, T., \& Hansen, K. Y. (2018). School characteristics moderating the relation between student socio-economic status and mathematics achievement in grade 8 . Evidence from 50 countries in TIMSS 2011. Studies in Educational Evaluation, 57, 1630. https://doi.org/10.1016/j.stueduc.2016.09.004

Harwell, M., Maeda, Y., Bishop, K., \& Xie, A. (2017). The surprisingly modest relationship between SES and educational achievement. Journal of Experimental Education, 85(2), 197-214. https://doi.org/10.1080/00220973.2015.1123668

Hattie, J., Rogers, H. J., \& Swaminathan, H. (2014). The Role of Meta-analysis in Educational Research. In A. D. Reid, E. P. Hart, \& M. A. Peters (Eds.), A Companion to Research in Education (pp. 197-207). Springer Netherlands. https://doi.org/10.1007/978-94-007$\underline{6809-3 \quad 26}$

Hedges, L. V. (2007). Effect Sizes in Cluster-Randomized Designs. Journal of Educational and Behavioral Statistics, 32(4), 341-370. https://doi.org/10.3102/1076998606298043

Hedges, L. V., Tipton, E., \& Johnson, M. C. (2010). Robust variance estimation in metaregression with dependent effect size estimates. Research Synthesis Methods, 1(1), 39-65. https://doi.org/10.1002/jrsm.5

Higgins, J. P. T., Thomas, J., Chandler, J., Cumpston, M., Li, T., Page, M. J., \& Welch, V. A. (2019). Cochrane Handbook for Systematic Reviews of Interventions. Wiley. https://doi.org/10.1002/9781119536604 
Hofstede, G. (2001). Culture’s Consequences: Comparing Values, Behaviors, Institutions and Organizations Across Nations. Thousand Oaks.

Hopfenbeck, T. N., Lenkeit, J., El Masri, Y., Cantrell, K., Ryan, J., \& Baird, J.-A. (2018).

Lessons Learned from PISA: A Systematic Review of Peer-Reviewed Articles on the Programme for International Student Assessment. Scandinavian Journal of Educational Research, 62(3), 333-353. https://doi.org/10.1080/00313831.2016.1258726

Keller, L., Preckel, F., Eccles, J., \& Brunner, M. (2020). Top-Performing Math Students in 82 Countries: A Meta-Analysis of Gender Differences in Achievement, Achievement Profiles, and Achievement Motivation. https://doi.org/10.31234/osf.io/73wap

Kim, J.-S., Anderson, C. J., \& Keller, B. (2012). Multilevel Analysis of Assessment Data. In L. Rutkowski, M. von Davier, \& D. Rutkowski (Eds.), Handbook of International LargeScale Assessment: Background, Technical Issues, and Methods of Data Analysis (pp. 390425). CRC Press.

Kim, S. w., Cho, H., \& Kim, L. Y. (2019). Socioeconomic Status and Academic Outcomes in Developing Countries: A Meta-Analysis. Review of Educational Research, 89(6), 875916. https://doi.org/10.3102/0034654319877155

Klieme, E. (2013). The Role of Large-Scale Assessments in Research on Educational Effectiveness and School Development. In M. von Davier, E. Gonzalez, I. Kirsch, \& K. Yamamoto (Eds.), The Role of International Large-Scale Assessments: Perspectives from Technology, Economy, and Educational Research (pp. 115-147). Springer Netherlands. https://doi.org/10.1007/978-94-007-4629-9 7

Klieme, E. (2020). Policies and Practices of Assessment: A Showcase for the Use (and Misuse) of International Large Scale Assessments in Educational Effectiveness Research. In J. 
Hall, A. Lindorff, \& P. Sammons (Eds.), International Perspectives in Educational Effectiveness Research (pp. 147-181). Springer International Publishing. https://doi.org/10.1007/978-3-030-44810-3_ 7

Kuger, S., \& Klieme, E. (2016). Dimensions of Context Assessment. In S. Kuger, E. Klieme, N. Jude, \& D. Kaplan (Eds.), Assessing Contexts of Learning: An International Perspective (pp. 3-37). Springer International Publishing. https://doi.org/10.1007/978-3-319-45357$\underline{6 \quad 1}$

Lai, M. H. C., \& Kwok, O.-m. (2016). Estimating Standardized Effect Sizes for Two- and ThreeLevel Partially Nested Data. Multivariate Behavioral Research, 51(6), 740-756. https://doi.org/10.1080/00273171.2016.1231606

Lenkeit, J., Chan, J., Hopfenbeck, T. N., \& Baird, J.-A. (2015). A review of the representation of PIRLS related research in scientific journals. Educational Research Review, 16, 102-115. https://doi.org/10.1016/j.edurev.2015.10.002

Letourneau, N. L., Duffett-Leger, L., Levac, L., Watson, B., \& Young-Morris, C. (2013). Socioeconomic status and child development: A meta-analysis. Journal of Emotional and Behavioral Disorders, 21(3), 211-224. https://doi.org/10.1177/1063426611421007

Lietz, P. (2006). A Meta-Analysis of Gender Differences in Reading Achievement at the Secondary School Level. Studies in Educational Evaluation, 32(4), 317-344. https://doi.org/10.1016/j.stueduc.2006.10.002

Lindberg, S. M., Hyde, J. S., Petersen, J. L., \& Linn, M. C. (2010). New trends in gender and mathematics performance: A meta-analysis. Psychological Bulletin, 136(6), 1123-1135. https://doi.org/10.1037/a0021276 
Liu, J., Peng, P., \& Luo, L. (2020). The relation between family socioeconomic status and academic achievement in China: A meta-analysis. Educational Psychology Review, 32, 49-76. https://doi.org/10.1007/s10648-019-09494-0

Möller, J., Zitzmann, S., Helm, F., Machts, N., \& Wolff, F. (2020). A Meta-Analysis of Relations Between Achievement and Self-Concept. Review of Educational Research, 90(3), 376419. https://doi.org/10.3102/0034654320919354

Morrison, A., Polisena, J., Husereau, D., Moulton, K., Clark, M., Fiander, M., MierzwinskiUrban, M., Clifford, T., Hutton, B., \& Rabb, D. (2012). The effect of English-language restriction on systematic review-based meta-analyses: a systematic review of empirical studies. Int J Technol Assess Health Care, 28(2), 138-144. https://doi.org/10.1017/s0266462312000086

Musu, L., Dohr, S., \& Netten, A. (2020). Quality Control During Data Collection: Refining for Rigor. In H. Wagemaker (Ed.), Reliability and Validity of International Large-Scale Assessment : Understanding IEA's Comparative Studies of Student Achievement (pp. 131150). Springer International Publishing. https://doi.org/10.1007/978-3-030-53081-5_8

Nilsen, T., Bloemeke, S., Yang Hansen, K., \& Gustafsson, J.-E. (2016). Are school characteristics related to equity? The answer may depend on a country's developmental level. IEA Policy Briefs, 10. https://www.iea.nl/publications/series-journals/policybrief/april-2016-are-school-characteristics-related-equity

OECD. (2016). PISA 2015 Results (Volume I): Excellence and Equity in Education. OECD Publishing. https://doi.org/10.1787/9789264266490-en

OECD. (2019). PISA 2018 Results (Volume II): Where All Students Can Succeed. OECD Publishing. https://doi.org/10.1787/b5fd1b8f-en 
OECD, \& netFWD. (2019). Quality Education for All: Lessons and Future Priorities. OECD Publishing. http://www.oecd.org/site/netfwd/NetFWD PolicyNoteOnEducation.pdf

Oh, I.-S. (2020). Beyond Meta-Analysis: Secondary Uses of Meta-Analytic Data. Annual Review of Organizational Psychology and Organizational Behavior, 7(1), 125-153. https://doi.org/10.1146/annurev-orgpsych-012119-045006

Peng, P., Wang, T., Wang, C., \& Lin, X. (2019). A meta-analysis on the relation between fluid intelligence and reading/mathematics: Effects of tasks, age, and social economics status. Psychological Bulletin, 145(2), 189-236. https://doi.org/10.1037/bul0000182

Petersen, J. (2018). Gender Difference in Verbal Performance: a Meta-analysis of United States State Performance Assessments. Educational Psychology Review, 30(4), 1269-1281. https://doi.org/10.1007/s10648-018-9450-x

Pigott, T. D., \& Polanin, J. R. (2020). Methodological Guidance Paper: High-Quality MetaAnalysis in a Systematic Review. Review of Educational Research, 90(1), 24-46. https://doi.org/10.3102/0034654319877153

Polanin, J. R., Espelage, D. L., Grotpeter, J. K., Spinney, E., Ingram, K. M., Valido, A., El Sheikh, A., Torgal, C., \& Robinson, L. (2020). A meta-analysis of longitudinal partial correlations between school violence and mental health, school performance, and criminal or delinquent acts. Psychological Bulletin. https://doi.org/10.1037/bul0000314

Pustejovsky, J. E., \& Tipton, E. (2021). Meta-Analysis with Robust Variance Estimation: Expanding the Range of Working Models. MetaArXiv Preprints. https://doi.org/10.31222/osf.io/vyfcj

Rios, J. A., Ihlenfeldt, S. D., Dosedel, M., \& Riegelman, A. (2020). A Topical and Methodological Systematic Review of Meta-Analyses Published in the Educational 
Measurement Literature. Educational Measurement: Issues and Practice, 39(1), 71-81. https://doi.org/10.1111/emip.12282

Rodríguez-Hernández, C. F., Cascallar, E., \& Kyndt, E. (2020). Socio-economic status and academic performance in higher education: A systematic review. Educational Research Review, 29, 100305. https://doi.org/10.1016/j.edurev.2019.100305

Röver, C. (2020). Bayesian Random-Effects Meta-Analysis Using the bayesmeta R Package. Journal of Statistical Software, 1(6), 1-51. https://doi.org/10.18637/jss.v093.i06

Rubio-Aparicio, M., López-López, J. A., Viechtbauer, W., Marín-Martínez, F., Botella, J., \& Sánchez-Meca, J. (2020). Testing Categorical Moderators in Mixed-Effects Meta-analysis in the Presence of Heteroscedasticity. The Journal of Experimental Education, 88(2), 288-310. https://doi.org/10.1080/00220973.2018.1561404

Rust, K. (2014). Sampling, Weighting, and Variance Estimation in International Large-Scale Assessments. In L. Rutkowski, M. von Davier, \& D. Rutkowski (Eds.), Handbook of International Large-Scale Assessment: Background, Technical Issues, and Methods of Data Analysis (pp. 117-154). CRC Taylor \& Francis. https://doi.org/10.1201/b16061

Rutkowski, D., \& Delandshere, G. (2016). Causal inferences with large scale assessment data: using a validity framework. Large-scale Assessments in Education, 4(1), 6. https://doi.org/10.1186/s40536-016-0019-1

Rutkowski, L., Gonzalez, E., Joncas, M., \& von Davier, M. (2010). International Large-Scale Assessment Data: Issues in Secondary Analysis and Reporting. Educational Researcher, 39(2), 142-151. https://doi.org/10.3102/0013189X10363170 
Rutkowski, L., \& Rutkowski, D. (2016). A Call for a More Measured Approach to Reporting and Interpreting PISA Results. Educational Researcher, 45(4), 252-257. https://doi.org/10.3102/0013189X16649961

Rutkowski, L., Rutkowski, D., \& Liaw, Y.-L. (2019). The existence and impact of floor effects for low-performing PISA participants. Assessment in Education: Principles, Policy \& Practice, 26(6), 643-664. https://doi.org/10.1080/0969594X.2019.1577219

Scammacca, N., Roberts, G., \& Stuebing, K. K. (2014). Meta-Analysis With Complex Research Designs: Dealing With Dependence From Multiple Measures and Multiple Group Comparisons. Review of Educational Research, 84(3), 328-364. https://doi.org/10.3102/0034654313500826

Scherer, R., \& Siddiq, F. (2019). The relation between students' socioeconomic status and ICT literacy: Findings from a meta-analysis. Computers \& Education, 138, $13-32$. https://doi.org/10.1016/j.compedu.2019.04.011

Sharpe, D. (1997). Of apples and oranges, file drawers and garbage: Why validity issues in metaanalysis will not go away. Clinical Psychology Review, 17(8), 881-901. https://doi.org/10.1016/S0272-7358(97)00056-1

Siddaway, A. P., Wood, A. M., \& Hedges, L. V. (2019). How to Do a Systematic Review: A Best Practice Guide for Conducting and Reporting Narrative Reviews, Meta-Analyses, and Meta-Syntheses. Annual Review of Psychology, 70(1), 747-770. https://doi.org/10.1146/annurev-psych-010418-102803

Siddiq, F., \& Scherer, R. (2019). Is there a gender gap? A meta-analysis of the gender differences in students' ICT literacy. Educational Research Review, 27, 205-217. https://doi.org/10.1016/j.edurev.2019.03.007 
Sirin, S. R. (2005). Socioeconomic Status and Academic Achievement: A Meta-Analytic Review of Research. Review of Educational Research, 75(3), 417-453. https://doi.org/10.3102/00346543075003417

Slavin, R. E. (2008). Perspectives on Evidence-Based Research in Education-What Works? Issues in Synthesizing Educational Program Evaluations. Educational Researcher, 37(1), 5-14. https://doi.org/10.3102/0013189X08314117

Strietholt, R., \& Scherer, R. (2018). The Contribution of International Large-Scale Assessments to Educational Research: Combining Individual and Institutional Data Sources. Scandinavian Journal of Educational Research, 62(3), 368-385. https://doi.org/10.1080/00313831.2016.1258729

Tan, C. Y. (2017). Examining cultural capital and student achievement: Results of a metaanalytic review. Alberta Journal of Educational Research, 63(2), 139-159. http://ovidsp.ovid.com/ovidweb.cgi?T=JS\&PAGE=reference\&D=psyc14\&NEWS=N\&A $\underline{\mathrm{N}=2017-40094-002}$

Tan, C. Y., Peng, B., \& Lyu, M. (2019). What types of cultural capital benefit students' academic achievement at different educational stages? Interrogating the meta-analytic evidence. Educational Research Review, 28, 100289. https://doi.org/10.1016/j.edurev.2019.100289

Turner, R. M., Bird, S. M., \& Higgins, J. P. T. (2013). The Impact of Study Size on Metaanalyses: Examination of Underpowered Studies in Cochrane Reviews. PLOS ONE, 8(3), e59202. https://doi.org/10.1371/journal.pone.0059202

Tymms, P. (2004). Effect sizes in multilevel models. In I. Schagen \& K. Elliot (Eds.), But what does it mean? The use of effect sizes in educational research (pp. 55-66). National Foundation for Educational Research. 
UNESCO UIS. (2018). Handbook on Measuring Equity in Education. UNESCO Institute for Statistics.

van de Vijver, F. J. R., Jude, N., \& Kuger, S. (2019). Challenges in International Large-Scale Educational Surveys. In L. Suter, E. Smith, \& B. Denman (Eds.), The SAGE Handbook of Comparative Studies in Education (pp. 83-102). Sage Publications.

Van den Noortgate, W., López-López, J. A., Marín-Martínez, F., \& Sánchez-Meca, J. (2013). Three-level meta-analysis of dependent effect sizes. Behavior Research Methods, 45(2), 576-594. https://doi.org/10.3758/s13428-012-0261-6

van Ewijk, R., \& Sleegers, P. (2010). The effect of peer socioeconomic status on student achievement: A meta-analysis. Educational Research Review, 5(2), 134-150. https://doi.org/10.1016/j.edurev.2010.02.001

Voyer, D., \& Voyer, S. D. (2014). Gender differences in scholastic achievement: A meta-analysis. Psychological Bulletin, 140(4), 1174-1204. https://doi.org/10.1037/a0036620

Wagemaker, H. (2016). International Large-Scale Assessments: From Research to Policy. In L. Rutkowski, M. von Davier, \& D. Rutkowski (Eds.), Handbook of International LargeScale Assessment: Background, Technical Issues, and Methods of Data Analysis (pp. 1136). CRC Press.

Wagemaker, H. (2020). Study Design and Evolution, and the Imperatives of Reliability and Validity. In H. Wagemaker (Ed.), Reliability and Validity of International Large-Scale Assessment : Understanding IEA's Comparative Studies of Student Achievement (pp. 721). Springer International Publishing. https://doi.org/10.1007/978-3-030-53081-5_2 
Yamamoto, K., Shin, H. J., \& Khorramdel, L. (2018). Multistage Adaptive Testing Design in International Large-Scale Assessments. Educational Measurement: Issues and Practice, 37(4), 16-27. https://doi.org/10.1111/emip.12226 
Tables

\section{Table 1}

Characteristics of the meta-analyses on the gender differences in student achievement

\begin{tabular}{|c|c|c|c|c|c|c|c|c|c|}
\hline Reference & $n$ & $k$ & $\begin{array}{l}\text { Achievement } \\
\text { domain(s) }\end{array}$ & Data & Type(s) of ILSA & $\begin{array}{l}\text { Inclusion } \\
\text { approach }\end{array}$ & $\begin{array}{l}\text { Addressing } \\
\text { dependence }\end{array}$ & $\begin{array}{l}\text { Sensitivity } \\
\text { analyses }\end{array}$ & $\begin{array}{l}\text { Pooled effect } \\
\text { size(s) }\end{array}$ \\
\hline $\begin{array}{l}\text { Baye \& Monseur } \\
(2016)\end{array}$ & 36 & 1654 & $\begin{array}{l}\text { Mathematics, } \\
\text { Science, } \\
\text { Reading }\end{array}$ & $\begin{array}{l}\text { Only ILSA } \\
\text { data }\end{array}$ & $\begin{array}{l}\text { PISA 2000, PISA } \\
\text { 2003, PISA 2006, } \\
\text { PISA 2009, PISA } \\
\text { 2012, PIRLS } \\
\text { 2001, PIRLS } \\
\text { 2006, PIRLS } \\
\text { 2011, TIMSS } \\
\text { 1995, TIMSS } \\
\text { 1999, TIMSS } \\
\text { 2003, TIMSS } \\
2007\end{array}$ & $\begin{array}{l}\text { Only } \\
\text { ILSA data }\end{array}$ & No & No & $\begin{array}{l}d=-0.06-0.34 \\
V R=1.12-1.15\end{array}$ \\
\hline $\begin{array}{l}\text { Else-Quest et al. } \\
(2010)\end{array}$ & 2 & 476 & Mathematics & $\begin{array}{l}\text { Only ILSA } \\
\text { data }\end{array}$ & $\begin{array}{l}\text { TIMSS 2003, } \\
\text { PISA } 2003\end{array}$ & $\begin{array}{l}\text { Only } \\
\text { ILSA data }\end{array}$ & No & No & $d=-0.42-0.40$ \\
\hline
\end{tabular}




\begin{tabular}{|c|c|c|c|c|c|c|c|c|c|}
\hline Keller et al. (2020) & 6 & 1028 & $\begin{array}{l}\text { Mathematics, } \\
\text { Science, } \\
\text { Reading }\end{array}$ & $\begin{array}{l}\text { Only ILSA } \\
\text { data }\end{array}$ & $\begin{array}{l}\text { PISA 2000, PISA } \\
\text { 2003, PISA 2006, } \\
\text { PISA 2009, PISA } \\
\text { 2012, PISA } 2015\end{array}$ & $\begin{array}{l}\text { Only } \\
\text { ILSA data }\end{array}$ & $\begin{array}{l}\text { Yes (three- } \\
\text { level REM) }\end{array}$ & No & $d=-0.23-0.05$ \\
\hline Lietz (2006) & 31 & 139 & Reading & $\begin{array}{l}\text { ILSA and } \\
\text { Non-ILSA }\end{array}$ & $\begin{array}{l}\text { IEA RC 1970/71, } \\
\text { IEA RL 1990/91, } \\
\text { PISA } 2000\end{array}$ & $\begin{array}{l}\text { One-stage } \\
\text { direct } \\
\text { inclusion }\end{array}$ & No & No & $d=0.19$ \\
\hline $\begin{array}{l}\text { Lindberg et al. } \\
(2010)\end{array}$ & 242 & 441 & Mathematics & $\begin{array}{l}\text { Only Non- } \\
\text { ILSA data }\end{array}$ & - & None & No & - & $d=-0.15-0.22$ \\
\hline $\begin{array}{l}\text { Ouma \& Nam } \\
(2015)\end{array}$ & 6 & 35 & $\begin{array}{l}\text { Mathematics, } \\
\text { Reading }\end{array}$ & $\begin{array}{l}\text { Only Non- } \\
\text { ILSA data }\end{array}$ & $\begin{array}{l}\text { SACMEQ I 2003, } \\
\text { SACMEQ I 2006, } \\
\text { SACMEQ I 2008; } \\
\text { SACMEQ II 2005, } \\
\text { SACMEQ II 2007, } \\
\text { SACMEQ II } 2009\end{array}$ & $\begin{array}{l}\text { One-stage } \\
\text { direct } \\
\text { inclusion }\end{array}$ & No & - & $d=-0.06-0.08$ \\
\hline $\begin{array}{l}\text { Siddiq \& Scherer } \\
(2019)\end{array}$ & 23 & 46 & Digital literacy & $\begin{array}{l}\text { ILSA and } \\
\text { Non-ILSA }\end{array}$ & ICILS 2013 & $\begin{array}{l}\text { One-stage } \\
\text { direct } \\
\text { inclusion }\end{array}$ & No & $\begin{array}{l}\text { Yes (two- } \\
\text { stage } \\
\text { direction } \\
\text { inclusion) }\end{array}$ & $g=0.12$ \\
\hline
\end{tabular}

Note. $n=$ Number of primary studies, $k=$ Number of effect sizes, ILSA = International large-scale assessment, $d=$ Cohen's $d, g=$ Hedges' $g, V R=$ Variance ratio, PISA = Programme for International Student Assessment, TIMSS = Trends in International Mathematics and Science Study, ICILS = International Computer and Information Literacy Study, PIRLS = Progress in International Reading Literacy Study, SACMEQ = Southern and Eastern Africa Consortium for Monitoring Educational Quality, IEA = International Association for the Evaluation of Educational Achievement, RC = Reading Comprehension Study, RL = Reading Literacy Study, REM = Random-effects model. 
Table 2

Characteristics of the meta-analyses on the relation between socioeconomic status and student achievement

\begin{tabular}{|c|c|c|c|c|c|c|c|c|c|c|}
\hline Reference & $n$ & $k$ & $\begin{array}{l}\text { Achievement } \\
\text { domain(s) }\end{array}$ & SES measure(s) & Data & $\begin{array}{l}\text { Type(s) of } \\
\text { ILSA }\end{array}$ & $\begin{array}{l}\text { Inclusion } \\
\text { approach }\end{array}$ & $\begin{array}{l}\text { Addressing } \\
\text { dependence }\end{array}$ & $\begin{array}{l}\text { Sensitivity } \\
\text { analyses }\end{array}$ & $\begin{array}{l}\text { Pooled } \\
\text { effect } \\
\text { size(s) }\end{array}$ \\
\hline $\begin{array}{l}\text { Harwell et al. } \\
\text { (2017) }\end{array}$ & 143 & 297 & $\begin{array}{l}\text { Mathematics, } \\
\text { Science, } \\
\text { Literacy, } \\
\text { General } \\
\text { disciplines }\end{array}$ & $\begin{array}{l}\text { Parent education, } \\
\text { parent occupation, } \\
\text { home resources, } \\
\text { free/reduced-price } \\
\text { lunches, } \\
\text { composite SES } \\
\text { indices }\end{array}$ & $\begin{array}{l}\text { Non- } \\
\text { ILSA } \\
\text { data }\end{array}$ & - & - & No & No & $r=0.12-0.26$ \\
\hline Kim et al. (2019) & 49 & 49 & $\begin{array}{l}\text { General } \\
\text { achievement, } \\
\text { Educational } \\
\text { attainment }\end{array}$ & $\begin{array}{l}\text { Parent education, } \\
\text { parent occupation, } \\
\text { home resources } \\
\text { and wealth } \\
\text { indices, } \\
\text { composite SES } \\
\text { indices }\end{array}$ & $\begin{array}{l}\text { ILSA } \\
\text { and } \\
\text { non- } \\
\text { ILSA } \\
\text { data }\end{array}$ & $\begin{array}{l}\text { PISA, } \\
\text { TIMSS, } \\
\text { SACMEQ, } \\
\text { MICS, } \\
\text { Young Lives } \\
\text { International } \\
\text { Longitudinal } \\
\text { Study }\end{array}$ & $\begin{array}{l}\text { One-stage } \\
\text { direct } \\
\text { inclusion }\end{array}$ & No & No & $r=0.08-0.20$ \\
\hline $\begin{array}{l}\text { Letourneau et al. } \\
\text { (2011) }\end{array}$ & 7 & 7 & $\begin{array}{l}\text { Literacy, } \\
\text { General } \\
\text { cognitive } \\
\text { skills }\end{array}$ & $\begin{array}{l}\text { Parent education, } \\
\text { parent occupation, } \\
\text { home resources } \\
\text { and wealth } \\
\text { indices, } \\
\text { composite SES } \\
\text { indices }\end{array}$ & $\begin{array}{l}\text { Non- } \\
\text { ILSA } \\
\text { data }\end{array}$ & - & - & No & No & $g=0.35$ \\
\hline Liu et al. (2020) & 78 & 480 & $\begin{array}{l}\text { Mathematics, } \\
\text { Science, } \\
\text { Chinese, } \\
\text { English, } \\
\text { General } \\
\text { achievement }\end{array}$ & $\begin{array}{l}\text { Parent education, } \\
\text { parent occupation, } \\
\text { home resources } \\
\text { and wealth } \\
\text { indices, income, } \\
\text { composite SES } \\
\text { indices }\end{array}$ & $\begin{array}{l}\text { ILSA } \\
\text { and } \\
\text { non- } \\
\text { ILSA } \\
\text { data }\end{array}$ & $\begin{array}{l}\text { PISA 2009, } \\
\text { PISA 2012, } \\
\text { PISA 2015 }\end{array}$ & $\begin{array}{l}\text { One-stage } \\
\text { direct } \\
\text { inclusion }\end{array}$ & $\begin{array}{l}\text { Yes (robust } \\
\text { variance } \\
\text { estimation) }\end{array}$ & No & $r=0.18-0.29$ \\
\hline
\end{tabular}




\begin{tabular}{|c|c|c|c|c|c|c|c|c|c|c|}
\hline $\begin{array}{l}\text { Rodríguez- } \\
\text { Hernández et al. } \\
\text { (2020) }\end{array}$ & 23 & 23 & $\begin{array}{l}\text { General } \\
\text { achievement, } \\
\text { Persistence }\end{array}$ & $\begin{array}{l}\text { Parent education, } \\
\text { parent occupation, } \\
\text { parent income, } \\
\text { home resources, } \\
\text { neighborhood } \\
\text { resources }\end{array}$ & $\begin{array}{l}\text { Non- } \\
\text { ILSA } \\
\text { data }\end{array}$ & - & - & No & No & $r=0.06$ \\
\hline $\begin{array}{l}\text { Scherer \& Siddiq } \\
\text { (2019) }\end{array}$ & 11 & 75 & $\begin{array}{l}\text { Digital } \\
\text { literacy }\end{array}$ & $\begin{array}{l}\text { Parent education, } \\
\text { parent occupation, } \\
\text { home resources } \\
\text { and wealth } \\
\text { indices, income, } \\
\text { composite SES } \\
\text { indices }\end{array}$ & $\begin{array}{l}\text { ILSA } \\
\text { and } \\
\text { non- } \\
\text { ILSA } \\
\text { data }\end{array}$ & ICILS 2013 & $\begin{array}{l}\text { One-stage } \\
\text { direct } \\
\text { inclusion }\end{array}$ & $\begin{array}{l}\text { Yes (three- } \\
\text { level } \\
\text { random- } \\
\text { effects } \\
\text { modeling) }\end{array}$ & $\begin{array}{l}\text { Yes (two- } \\
\text { stage } \\
\text { direct } \\
\text { inclusion, } \\
\text { exclusion } \\
\text { of ILSA } \\
\text { data) }\end{array}$ & $r=0.18-0.25$ \\
\hline Sirin (2005) & 58 & 167 & $\begin{array}{l}\text { Mathematics, } \\
\text { Science, } \\
\text { Literacy, } \\
\text { General } \\
\text { disciplines }\end{array}$ & $\begin{array}{l}\text { Parent education, } \\
\text { parent occupation, } \\
\text { home resources } \\
\text { and wealth } \\
\text { indices, income, } \\
\text { neighborhood, } \\
\text { free or reduced- } \\
\text { price lunches, } \\
\text { home }\end{array}$ & $\begin{array}{l}\text { Non- } \\
\text { ILSA } \\
\text { data }\end{array}$ & - & - & No & - & $r=0.25-0.51$ \\
\hline Tan (2017) & 52 & 155 & $\begin{array}{l}\text { Mathematics, } \\
\text { Science, } \\
\text { Literacy }\end{array}$ & $\begin{array}{l}\text { Home educational } \\
\text { resources, cultural } \\
\text { participation, } \\
\text { reading at home } \\
\text { or outside school, } \\
\text { parent-child } \\
\text { cultural } \\
\text { discussions, } \\
\text { educational } \\
\text { expectations, } \\
\text { parent home and } \\
\text { school } \\
\text { involvement, }\end{array}$ & $\begin{array}{l}\text { ILSA } \\
\text { and } \\
\text { non- } \\
\text { ILSA } \\
\text { data }\end{array}$ & TIMSS 1999 & $\begin{array}{l}\text { One-stage } \\
\text { direct } \\
\text { inclusion }\end{array}$ & No & No & $\begin{array}{l}r=-0.02- \\
0.38\end{array}$ \\
\hline
\end{tabular}




\begin{tabular}{|c|c|c|c|c|c|c|c|c|c|c|}
\hline & & & & $\begin{array}{l}\text { parent educational } \\
\text { attainment }\end{array}$ & & & & & & \\
\hline Tan et al. (2019) & 105 & 190 & $\begin{array}{l}\text { Mathematics, } \\
\text { Science, } \\
\text { Literacy }\end{array}$ & $\begin{array}{l}\text { Home educational } \\
\text { resources, cultural } \\
\text { participation, } \\
\text { reading at home } \\
\text { or outside school, } \\
\text { parent-child } \\
\text { cultural } \\
\text { discussions, } \\
\text { educational } \\
\text { expectations, } \\
\text { parent home and } \\
\text { school } \\
\text { involvement, } \\
\text { parent educational } \\
\text { attainment, } \\
\text { composite SES } \\
\text { indices }\end{array}$ & $\begin{array}{l}\text { ILSA } \\
\text { and } \\
\text { non- } \\
\text { ILSA } \\
\text { data }\end{array}$ & TIMSS 1999 & $\begin{array}{l}\text { One-stage } \\
\text { direct } \\
\text { inclusion }\end{array}$ & No & No & $r=0.00-0.37$ \\
\hline $\begin{array}{l}\text { Van Ewijk et al. } \\
\text { (2010) }\end{array}$ & 30 & 188 & $\begin{array}{l}\text { Mathematics, } \\
\text { Science, } \\
\text { Literacy, } \\
\text { Social } \\
\text { Sciences, } \\
\text { Economics, } \\
\text { General } \\
\text { achievement }\end{array}$ & $\begin{array}{l}\text { Parent education, } \\
\text { parent occupation, } \\
\text { home resources, } \\
\text { composite SES } \\
\text { indices }\end{array}$ & $\begin{array}{l}\text { ILSA } \\
\text { and } \\
\text { non- } \\
\text { ILSA } \\
\text { data }\end{array}$ & $\begin{array}{l}\text { PISA 2000, } \\
\text { PISA } 2003\end{array}$ & $\begin{array}{l}\text { One-stage } \\
\text { direct } \\
\text { inclusion }\end{array}$ & $\begin{array}{l}\text { Yes } \\
\text { (weighted } \\
\text { meta- } \\
\text { regression } \\
\text { model) }\end{array}$ & $\begin{array}{l}\text { Yes } \\
\text { (exclusion } \\
\text { of ILSA } \\
\text { data) }\end{array}$ & $r=0.32$ \\
\hline
\end{tabular}

Note. $n=$ Number of primary studies, $k=$ Number of effect sizes, ILSA $=$ International large-scale assessment, $g=$ Hedges' $g, r=$ Pearson correlation, SES $=$ Socioeconomic status. 
Table 3

Review of the Different Inclusion Approaches

\begin{tabular}{|c|c|c|c|c|}
\hline & \multirow[t]{2}{*}{ Separate meta-analyses } & \multicolumn{2}{|c|}{ Direct inclusion } & \multirow[t]{2}{*}{ Indirect inclusion } \\
\hline & & One-stage inclusion & Two-stage inclusion & \\
\hline Description & $\begin{array}{l}\text { Primary effect sizes obtained } \\
\text { from ILSA and non-ILSA data } \\
\text { are meta-analyzed separately } \\
\text { and considered as different } \\
\text { meta-analytic data sets }\end{array}$ & $\begin{array}{l}\text { Primary effect sizes obtained } \\
\text { from ILSA and non-ILSA } \\
\text { data are directly included in } \\
\text { the meta-analyses, allowing } \\
\text { for multiple effect sizes per } \\
\text { study, cycle, or country }\end{array}$ & $\begin{array}{l}\text { Stage 1: Primary effect } \\
\text { sizes obtained from ILSA } \\
\text { data are pooled } \\
\text { Stage 2: The pooled ILSA } \\
\text { effect size(s) and the } \\
\text { primary effect sizes of the } \\
\text { non-ILSA data are meta- } \\
\text { analyzed. }\end{array}$ & $\begin{array}{l}\text { Primary effect sizes obtained } \\
\text { from ILSA data are meta- } \\
\text { analyzed in the first step, and } \\
\text { the resultant overall effect size } \\
\text { and/or variance estimates } \\
\text { inform the meta-analysis of } \\
\text { non-ILSA data as priors }\end{array}$ \\
\hline Analytic steps & $\begin{array}{l}\text { 1. Compute the primary } \\
\text { effect sizes for ILSA and } \\
\text { non-ILSA data, taking } \\
\text { into account the (complex) } \\
\text { study designs } \\
\text { 2. Identify the meta-analytic } \\
\text { data structures for the } \\
\text { ILSA and non-ILSA data } \\
\text { sets } \\
\text { 3. Synthesize the primary } \\
\text { effect sizes of the ILSA } \\
\text { data via (multilevel) } \\
\text { random-effects meta- } \\
\text { analysis and obtain the } \\
\text { overall effect size(s) and } \\
\text { variance component(s) for } \\
\text { the level of studies or } \\
\text { cycles (e.g., PISA or PISA } \\
\text { 2015) }\end{array}$ & $\begin{array}{l}\text { 1. Compute the primary } \\
\text { effect sizes for ILSA and } \\
\text { non-ILSA data, taking } \\
\text { into account the } \\
\text { (complex) study designs } \\
\text { 2. Combine the primary } \\
\text { effect-size ILSA and } \\
\text { non-ILSA data } \\
\text { 3. Identify the meta- } \\
\text { analytic data structure } \\
\text { 4. Quantify the overall } \\
\text { effect size and the } \\
\text { respective variance } \\
\text { component(s) via } \\
\text { (multilevel) random- } \\
\text { effects meta-analysis } \\
\text { 5. Examine the possible } \\
\text { differences in effect sizes } \\
\text { between ILSA and non- } \\
\text { ILSA data }\end{array}$ & $\begin{array}{l}\text { 1. Compute the primary } \\
\text { effect sizes for ILSA } \\
\text { and non-ILSA data, } \\
\text { taking into account the } \\
\text { (complex) study } \\
\text { designs } \\
\text { 2. Identify the meta- } \\
\text { analytic data structures } \\
\text { for the ILSA and non- } \\
\text { ILSA data sets } \\
\text { 3. Synthesize the primary } \\
\text { effect sizes of the ILSA } \\
\text { data via (multilevel) } \\
\text { random-effects meta- } \\
\text { analysis or other } \\
\text { aggregation approaches } \\
\text { and obtain the overall } \\
\text { effect size(s) and } \\
\text { variance component(s) } \\
\text { for the level of studies }\end{array}$ & $\begin{array}{l}\text { 1. Compute the primary effect } \\
\text { sizes for ILSA and non- } \\
\text { ILSA data, taking into } \\
\text { account the (complex) } \\
\text { study designs } \\
\text { 2. Identify the meta-analytic } \\
\text { data structures for the ILSA } \\
\text { and non-ILSA data sets } \\
\text { 3. Synthesize the primary } \\
\text { effect sizes of the ILSA } \\
\text { data via (multilevel) } \\
\text { random-effects meta- } \\
\text { analysis and obtain the } \\
\text { overall effect size(s) and } \\
\text { variance component(s) for } \\
\text { the level of studies or } \\
\text { cycles (e.g., PISA or PISA } \\
\text { 2015) } \\
\text { 4eta-analyze the primary } \\
\text { non-ILSA effect sizes via }\end{array}$ \\
\hline
\end{tabular}


4. Synthesize the primary effect sizes of the nonILSA data via (multilevel) random-effects metaanalysis and obtain the overall effect size(s) and variance component(s)

5. Conduct moderator analyses to identify possible sources of heterogeneity for ILSA and non-ILSA data separately

6. Examine publication bias and file-drawer issues for ILSA and non-ILSA data separately

Primary analytic approaches

Random-effects meta-analysis, meta-analysis with robust variance estimation

Multilevel random-effects meta-analysis, meta-analysis with robust variance estimation

analyses to identify other possible sources of heterogeneity

7. Examine publication bias and file-drawer issues

8. Conduct sensitivity analyses with respect to ignoring the hierarchical data structure vs. modeling this structure or cycles (e.g., PISA or

PISA 2015)

- Full information on the ILSA characteristics at the level of effect sizes can be incorporated

advantages

Less complex metaanalytic models are required to synthesize the data (e.g., within-ILSA variation is no longer estimated)—standard
4. Combine the synthesized ILSA effect sizes with the primary effect-size non-ILSA data

5. Quantify the overall effect size and the respective variance component(s) via random-effects metaanalysis

6. Conduct moderator analyses to identify possible sources of heterogeneity

7. Examine publication bias and file-drawer issues

8. Conduct sensitivity analyses with respect to excluding vs. including the synthesized effect size of the ILSA data

Random-effects metaanalysis, meta-analysis with robust variance estimation
- Less complex metaanalytic models are required to synthesize the data (e.g., withinILSA variation is no longer estimated)within studies or other
Bayesian random-effects meta-analysis using priors for the overall effect size and/or the variance component(s) that are informed by the overall effect size and variance component(s) of the ILSA data

5. Conduct moderator analyses to identify possible sources of heterogeneity

6. Examine publication bias and file-drawer issues

7. Conduct sensitivity analyses with respect to the choice of priors

Bayesian meta-analysis
- Less complex metaanalytic models are required to synthesize the data (e.g., within-ILSA variation is no longer estimated) entities can be quantified 


\begin{tabular}{|c|c|c|c|c|}
\hline $\begin{array}{l}\text { Key } \\
\text { challenges }\end{array}$ & $\begin{array}{l}\text { - Separate meta-analyses of } \\
\text { ILSA and non-ILSA data } \\
\text { do not inform each other } \\
\text { - Fewer studies available } \\
\text { for each of the separate } \\
\text { meta-analyses }\end{array}$ & $\begin{array}{l}\text { Moderator analyses at } \\
\text { different levels of } \\
\text { analysis are possible } \\
\text { - Comparisons of overall } \\
\text { effect sizes between } \\
\text { ILSA and non-ILSA data } \\
\text { possible via mixed- } \\
\text { effects models } \\
\text { Advanced meta-analytic } \\
\text { methods are needed (e.g., } \\
\text { multilevel random- and } \\
\text { mixed-effects meta- } \\
\text { analysis) }\end{array}$ & 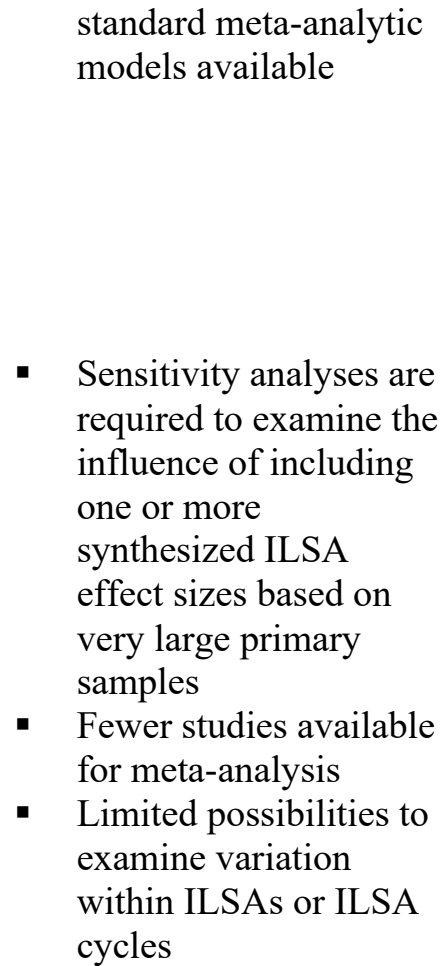 & 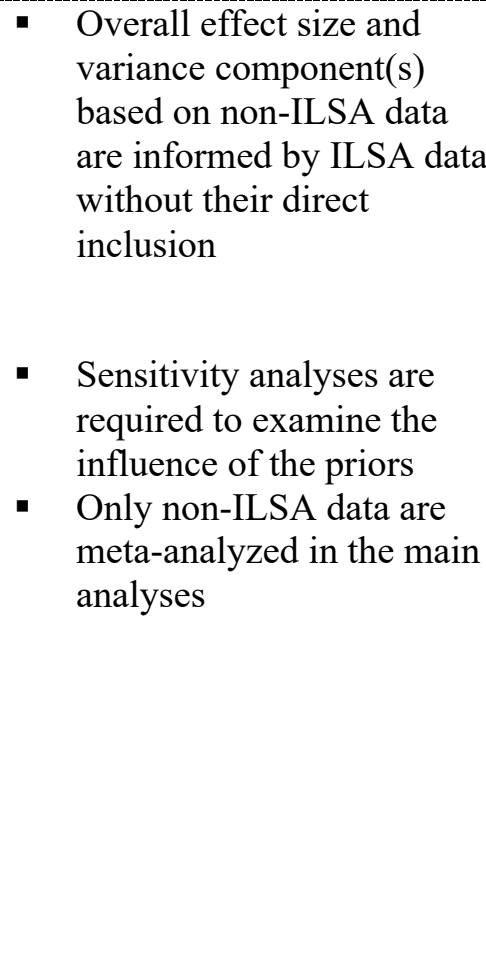 \\
\hline
\end{tabular}

Note. ILSA = International large-scale assessment. 


\section{Table 4}

Results of the random-effects meta-analyses of the gender differences in digital literacy

\begin{tabular}{|c|c|c|c|c|c|c|c|c|}
\hline & \multicolumn{4}{|c|}{ Separate meta-analyses } & \multicolumn{3}{|c|}{ Direct inclusion } & \multirow{2}{*}{$\begin{array}{c}\text { Indirect } \\
\text { inclusion } \\
\text { Bayesian } \\
\text { meta- } \\
\text { analysis }\end{array}$} \\
\hline & $\begin{array}{c}\text { ICILS } 2013 \\
\text { data }\end{array}$ & $\begin{array}{c}\text { ICILS } 2018 \\
\text { data }\end{array}$ & $\begin{array}{c}\text { ICILS } 2013 \\
\& 2018 \\
\text { data }\end{array}$ & $\begin{array}{c}\text { Non-ILSA } \\
\text { data }\end{array}$ & $\begin{array}{l}\text { One-stage } \\
\text { inclusion }\end{array}$ & $\begin{array}{l}\text { One-stage } \\
\text { inclusion }\end{array}$ & $\begin{array}{l}\text { Two-stage } \\
\text { inclusion }\end{array}$ & \\
\hline \multicolumn{9}{|l|}{$\begin{array}{l}\text { Weighted } \\
\text { average effect } \\
\text { size }\end{array}$} \\
\hline $\bar{g}$ & 0.13 & 0.21 & 0.16 & 0.12 & 0.13 & 0.10 & 0.12 & 0.12 \\
\hline $95 \% \mathrm{CI}$ & {$[0.10,0.17]$} & {$[0.15,0.27]$} & {$[0.12,0.19]$} & {$[0.04,0.20]$} & {$[0.05,0.21]$} & {$[0.01,0.18]$} & {$[0.05,0.19]$} & {$[0.03,0.20]$} \\
\hline$k$ & 21 & 13 & 34 & 25 & 59 & 59 & 27 & 25 \\
\hline$m$ & 21 & 13 & 28 & 25 & 24 & 24 & 27 & 25 \\
\hline \multicolumn{9}{|l|}{ Heterogeneity } \\
\hline$\tau_{(2)}^{2}$ & 0.005 & 0.012 & 0.003 & 0.033 & 0.007 & 0.016 & 0.030 & 0.036 \\
\hline $95 \% \mathrm{CI}$ & $\begin{array}{c}{[0.002,} \\
0.012]\end{array}$ & $\begin{array}{c}{[0.005,} \\
0.033]\end{array}$ & $\begin{array}{c}{[0.000,} \\
0.013]\end{array}$ & $\begin{array}{c}{[0.016,} \\
0.074]\end{array}$ & $\begin{array}{c}{[0.004,} \\
0.013]\end{array}$ & $\begin{array}{c}{[0.000,} \\
0.079]\end{array}$ & $\begin{array}{c}{[0.014,} \\
0.065]\end{array}$ & $\begin{array}{c}{[0.017,} \\
0.078]\end{array}$ \\
\hline$\tau_{(3)}^{2}$ & - & - & - & - & 0.027 & 0.031 & - & - \\
\hline $95 \% \mathrm{CI}$ & - & - & - & - & $\begin{array}{c}{[0.007} \\
0.071]\end{array}$ & $\begin{array}{c}{[0.011,} \\
0.077]\end{array}$ & - & - \\
\hline$\tau_{(4)}^{2}$ & - & - & 0.006 & - & - & 0.006 & - & - \\
\hline $95 \% \mathrm{CI}$ & - & - & $\begin{array}{c}{[0.000,} \\
0.015]\end{array}$ & - & - & $\begin{array}{c}{[0.000,} \\
0.012]\end{array}$ & - & - \\
\hline Baseline model & REM2 & REM2 & REM3 & REM2 & REM3 & CCREM4 & REM2 & REM2 \\
\hline
\end{tabular}

Note. ILSA = International large-scale assessment, $\bar{g}=$ Weighted average effect size of gender differences (Hedges' $g$ ), $k=$ Number of effect sizes (samples), $m=$ Number of studies, $\tau_{(2)}^{2}=$ Between-sample heterogeneity, $\tau_{(3)}^{2}=$ Between-study heterogeneity, $\tau_{(4)}^{2}=$ Between-country heterogeneity, REM2 = Two-level random-effects model, REM3 = Three-level random-effects model, CCREM4 = Four-level cross-classified random-effects model (with 31 countries). 


\section{Table 5}

Results of the mixed-effects meta-regression analyses including study-and country-level moderators

\begin{tabular}{|c|c|c|c|c|c|c|c|c|}
\hline & \multicolumn{4}{|c|}{ Separate meta-analyses } & \multicolumn{3}{|c|}{ Direct inclusion } & \multirow{2}{*}{$\begin{array}{c}\begin{array}{c}\text { Indirect } \\
\text { inclusion }\end{array} \\
\begin{array}{c}\text { Bayesian } \\
\text { meta-analysis }\end{array}\end{array}$} \\
\hline & $\begin{array}{c}\text { ICILS } 2013 \\
\text { data }\end{array}$ & $\begin{array}{c}\text { ICILS } 2018 \\
\text { data }\end{array}$ & $\begin{array}{l}\text { ICILS } 2013 \\
\& 2018 \text { data }\end{array}$ & $\begin{array}{c}\text { Non-ILSA } \\
\text { data }\end{array}$ & $\begin{array}{l}\text { One-stage } \\
\text { inclusion }\end{array}$ & $\begin{array}{l}\text { One-stage } \\
\text { inclusion }\end{array}$ & $\begin{array}{l}\text { Two-stage } \\
\text { inclusion }\end{array}$ & \\
\hline \multicolumn{9}{|l|}{$\begin{array}{l}\text { Regression } \\
\text { coefficients } \\
B(95 \% \mathrm{CI})\end{array}$} \\
\hline Intercept & $\begin{array}{c}-0.03 \\
{[-0.37,0.30]}\end{array}$ & $\begin{array}{c}-0.54 \\
{[-0.90,-.018]}\end{array}$ & $\begin{array}{c}-0.17 \\
{[-0.49,0.14]}\end{array}$ & $\begin{array}{c}-0.22 \\
{[-1.49,1.05]}\end{array}$ & $\begin{array}{c}-0.30 \\
{[-0.58,-0.02]}\end{array}$ & $\begin{array}{c}-0.28 \\
{[-0.57,0.02]}\end{array}$ & $\begin{array}{c}0.12 \\
{[0.01,0.22]}\end{array}$ & $\begin{array}{c}-0.21 \\
{[-1.57,1.15]}\end{array}$ \\
\hline Test fairness & - & - & - & $\begin{array}{c}0.20^{*} \\
{[0.01,0.39]}\end{array}$ & $\begin{array}{c}0.17 \\
{[-0.01,0.36]}\end{array}$ & $\begin{array}{c}0.18^{*} \\
{[0.00,0.36]}\end{array}$ & $\begin{array}{c}0.17^{*} \\
{[0.00,0.34]}\end{array}$ & $\begin{array}{c}0.20 \\
{[-0.01,0.41]}\end{array}$ \\
\hline Publication type & - & - & - & $\begin{array}{c}-0.24 * \\
{[-0.43,-0.05]}\end{array}$ & $\begin{array}{c}-0.21^{*} \\
{[-0.40,-0.01]}\end{array}$ & $\begin{array}{c}-0.21^{*} \\
{[-0.41,-0.01]}\end{array}$ & $\begin{array}{c}-0.22^{*} \\
{[-0.39,-0.05]}\end{array}$ & $\begin{array}{c}-0.24 * \\
{[-0.45,-0.04]}\end{array}$ \\
\hline $\begin{array}{r}\text { Power distance } \\
\text { index (PDI) }\end{array}$ & $\begin{array}{c}0.00 \\
{[0.00,0.01]}\end{array}$ & $\begin{array}{c}0.00 \\
{[0.00,0.01]}\end{array}$ & $\begin{array}{c}0.00 \\
{[0.00,0.00]}\end{array}$ & $\begin{array}{c}0.00 \\
{[0.00,0.01]}\end{array}$ & $\begin{array}{c}0.00 \\
{[0.00,0.00]}\end{array}$ & $\begin{array}{c}0.00 \\
{[0.00,0.00]}\end{array}$ & - & $\begin{array}{c}0.00 \\
{[0.00,0.01]}\end{array}$ \\
\hline $\begin{array}{r}\text { Global innovation } \\
\text { index (GII) }\end{array}$ & $\begin{array}{c}0.00 \\
{[0.00,0.01]}\end{array}$ & $\begin{array}{c}0.01^{*} \\
{[0.01,0.02]}\end{array}$ & $\begin{array}{c}0.01 * \\
{[0.00,0.01]}\end{array}$ & $\begin{array}{c}0.00 \\
{[-0.02,0.02]}\end{array}$ & $\begin{array}{c}0.01 * \\
{[0.00,0.01]}\end{array}$ & $\begin{array}{c}0.01 * \\
{[0.00,0.01]}\end{array}$ & - & $\begin{array}{c}0.00 \\
{[-0.02,0.02]}\end{array}$ \\
\hline Baseline model & MEM2 & MEM2 & MEM3 & MEM2 & MEM3 & CCMEM4 & MEM2 & MEM2 \\
\hline
\end{tabular}

Note. ILSA = International large-scale assessment. The results of the two-stage direct inclusion are based on the pooling of the ICILS 2013 and 2018 data via random-effects meta-analyses in the first stage. The GII was derived as the country average of the global innovation indices across publication years. PDI and GII are country-level variables, while test fairness and publication type are study- level variables. MEM2 = Two-level mixed-effects meta-regression model, MEM3 = Three-level mixed-effects meta-regression model, CCMEM4 = Fourlevel cross-classified mixed-effects meta-regression model (with 31 countries). ${ }^{*} p<.05$ 
Figures

\section{Figure 1}

PRISMA Flow Diagram of the Search, Screening, and Inclusion Processes of the Meta-Analyses

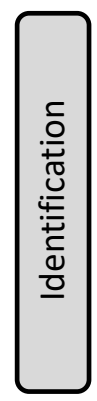

Records identified through database searching (ERIC, PsycINFO, PsyArXiv)

$\left(n_{\text {Gender }}=297, n_{S E S}=262\right)$

Additional records identified through

other sources (i.e., journals)

$\left(n_{\text {Gender }}=59, n_{S E S}=60\right)$

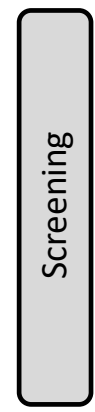

Records after duplicated removed

$\left(n_{\text {Gender }}=318, n_{\text {SES }}=271\right)$

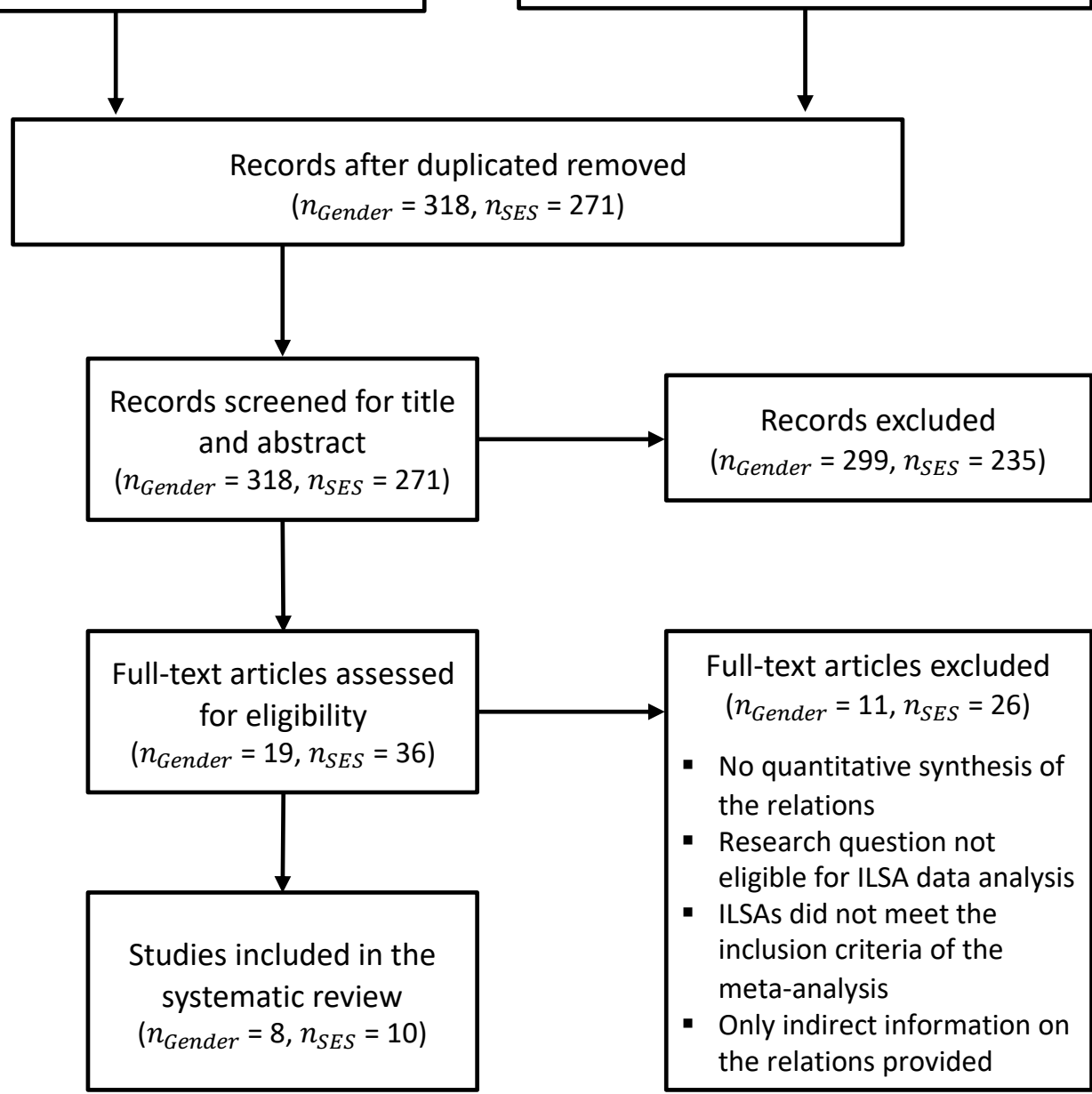

Note. ILSA = International large-scale assessment, $\mathrm{SES}=$ Socioeconomic status. 
Figure 2

Meta-analytic data structures: (a) Common hierarchical structure, (b) three-level hierarchical structure, and (c) cross-classified structure

(a) Common two-level hierarchical structure

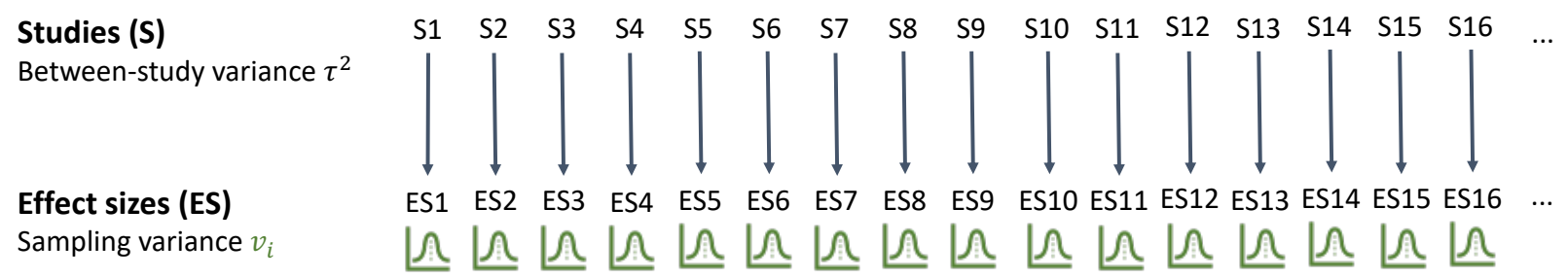

(b) Three-level hierarchical structure

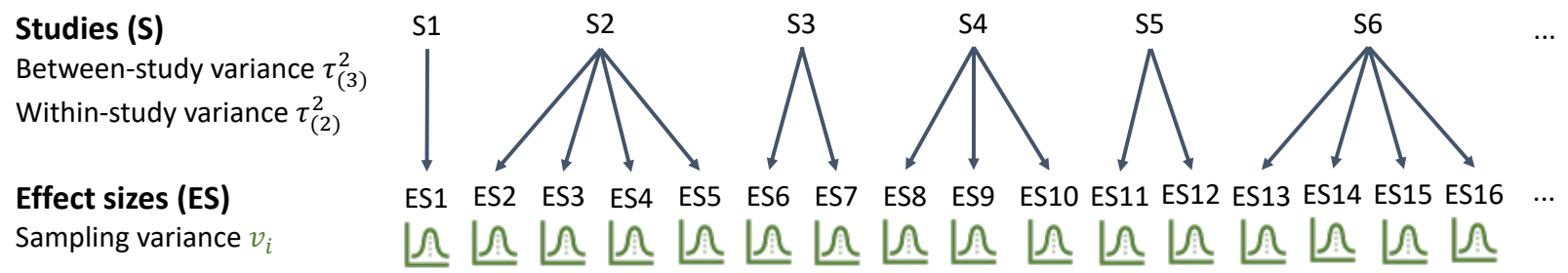

(c) Cross-classified non-hierarchical structure

Studies (S)
Between-study variance $\tau_{(3)}^{2}$
Within-study variance $\tau_{(2)}^{2}$

Effect sizes (ES)

Sampling variance $v_{i}$

Countries (C)

Between-country variance $\tau_{(4)}^{2}$
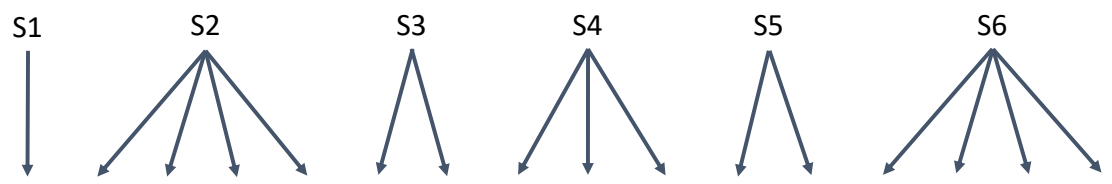

ES1 ES2 ES3 ES4 ES5 ES6 ES7 ES8

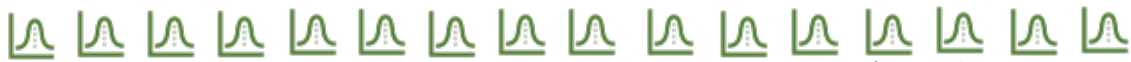

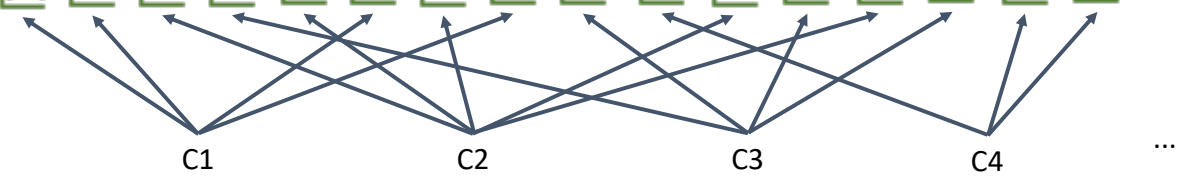




\section{Figure 3}

Overview of the (a) one-stage and (b) two-stage direct inclusion approaches

(a) One-Stage Direction Inclusion

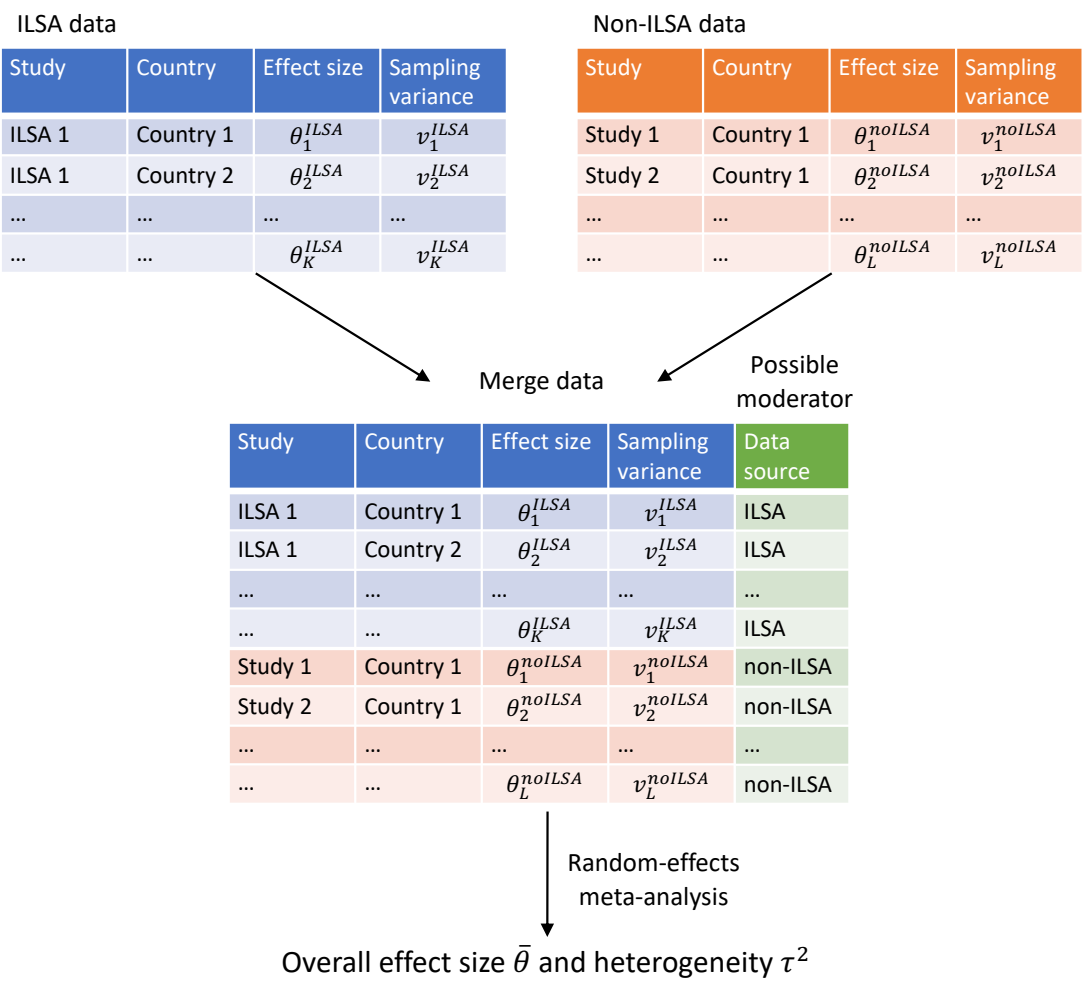

(b) Two-Stage Direction Inclusion

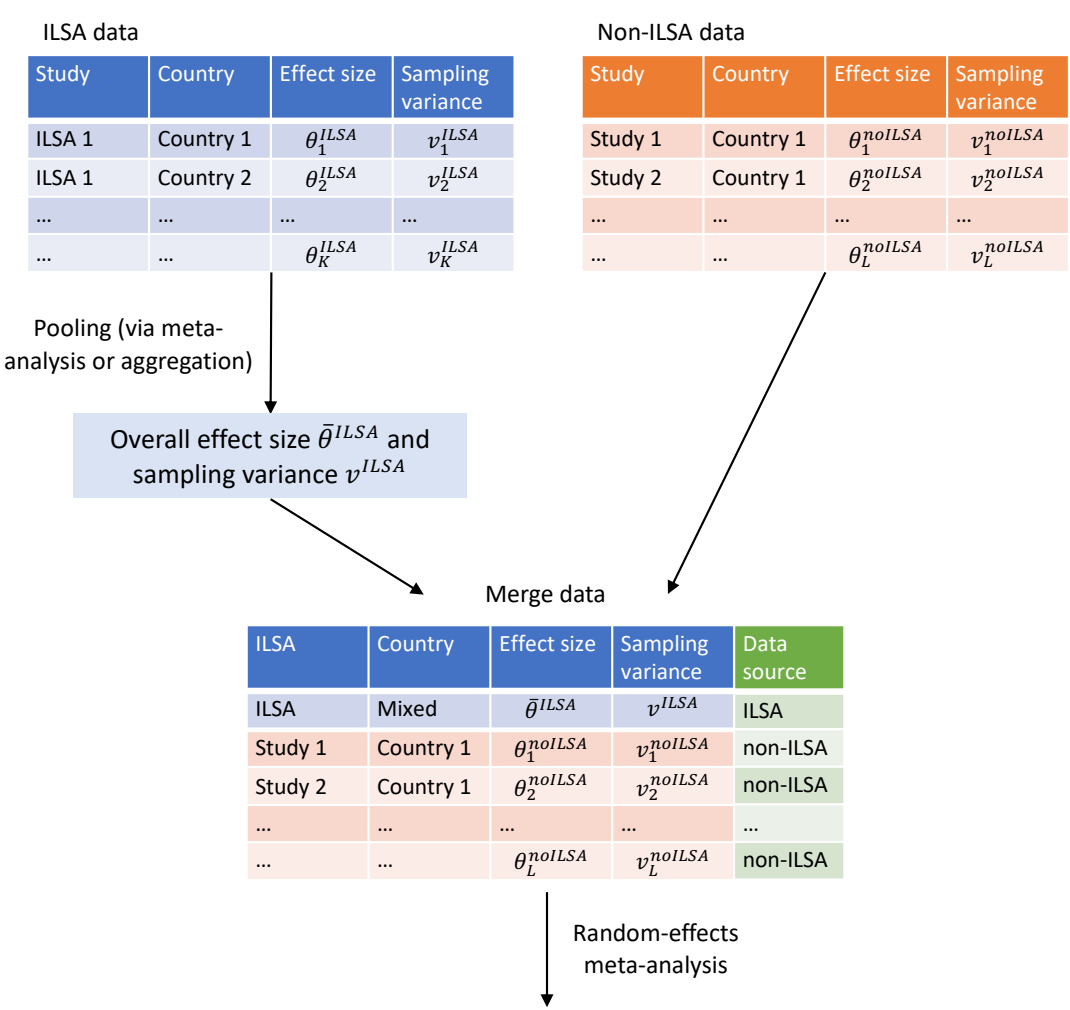

Overall effect size $\bar{\theta}$ and heterogeneity $\tau^{2}$

Note. ILSA = International large-scale assessment, $K=$ Number of effect sizes extracted from ILSAs, $L=$ Number of effect sizes extracted from the non-ILSA studies. 
Figure 4

Forest plots of the effect sizes for the ILSA and non-ILSA data

\section{(a) Effect Sizes of the Non-ILSA Data}

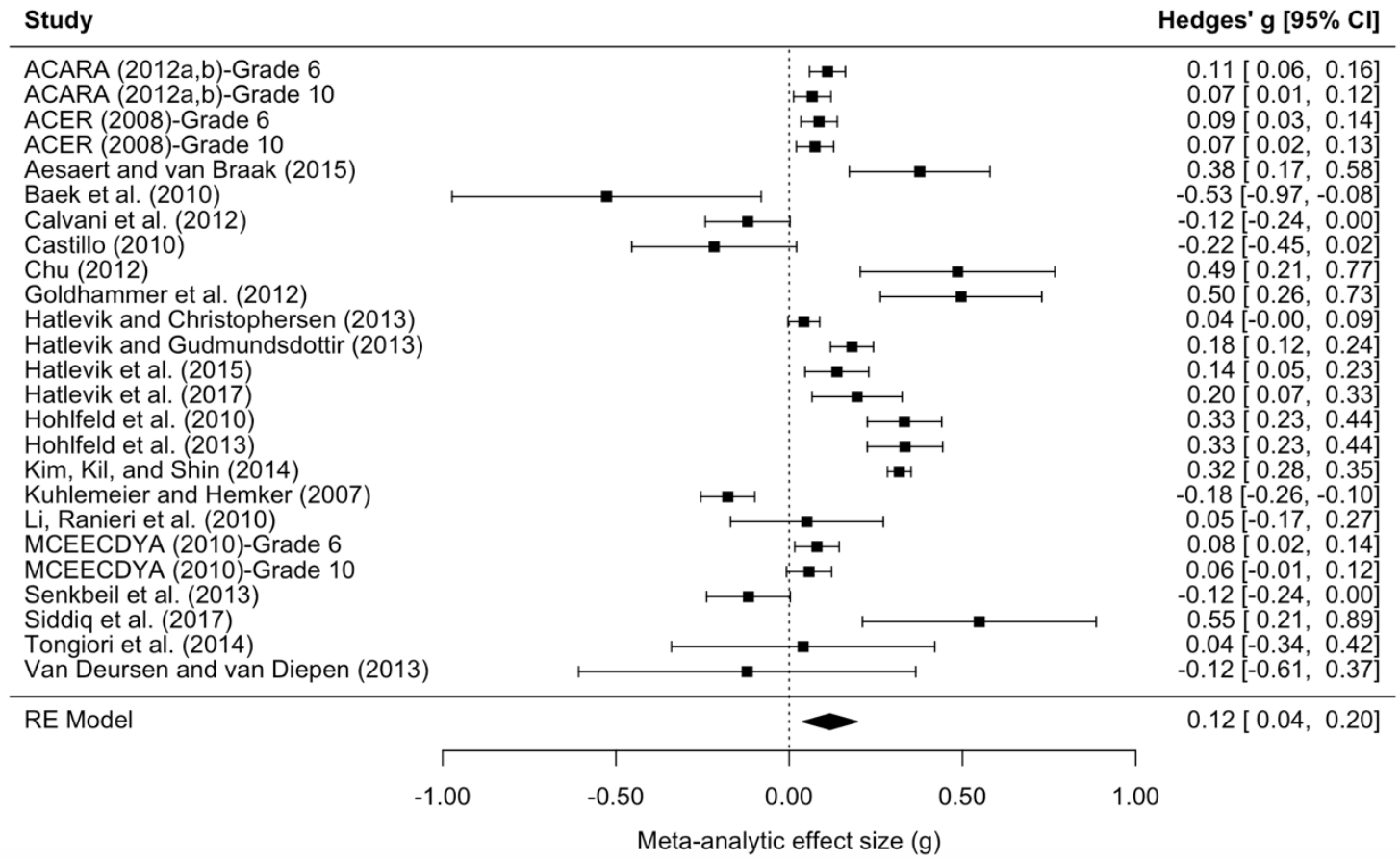

(b) Effect Sizes of the ICILS 2013 Data

Study

Hedges' g $[95 \% \mathrm{Cl}]$

ICILS 2013-Australia

ICILS 2013-Chile

ICILS 2013-Croatia

ICILS 2013-Czech Republic

ICILS 2013-Germany

ICILS 2013-Korea

ICILS 2013-Lithuania

ICILS 2013-Norway

ICILS 2013-Poland

ICILS 2013-Russian Federation

ICILS 2013-Slovak Republic

ICILS 2013-Slovenia

ICILS 2013-Thailand

ICILS 2013-Turkey

ICILS 2013-Denmark

ICILS 2013-Hong Kong SAR

ICILS 2013-The Netherlands

ICILS 2013-Switzerland

ICILS 2013-Newfoundland and Labrador

ICILS 2013-Ontario, CA

ICILS 2013-City of Buenos Aires

$0.16[0.10,0.21]$

$0.16[0.09,0.23]$

$0.12[0.04,0.19]$

$0.12[0.05,0.19]$

$0.16[0.07,0.24]$

$0.30[0.23,0.37$

$0.11[0.04,0.19]$

$0.22[0.14,0.30]$

$0.11[0.04,0.19]$

$0.10[0.03,0.16]$

$0.07[-0.00,0.14]$

$0.24[0.17,0.30]$

$0.04[-0.03,0.10]$

$0.01[-0.07,0.09]$

$0.11[0.02,0.20]$

$0.09[0.01,0.17$

$0.12[0.04,0.20]$

$0.03[-0.03,0.10]$

$0.32[0.22,0.42]$

$0.16[0.10,0.23]$

RE Model

$0.02[-0.08,0.12]$

$0.13[0.10,0.17]$

$\begin{array}{lll}-0.10 & 0.20 & 0.40\end{array}$

Meta-analytic effect size (g) 
(c) Effect Sizes of the ICILS 2018 Data

\begin{tabular}{|c|c|c|}
\hline Study & & Hedges' g $[95 \% \mathrm{Cl}]$ \\
\hline ICILS 2018-Chile & $\vdots \curvearrowleft-1$ & $0.10[0.03,0.17]$ \\
\hline ICILS 2018-Denmark & $\mapsto$ & $0.25[0.17,0.33]$ \\
\hline ICILS 2018-Finland & $\mapsto$ & $0.37[0.29,0.44]$ \\
\hline ICILS 2018-France & $\mapsto$ & $0.30[0.23,0.37]$ \\
\hline ICILS 2018-Germany & $\mapsto-1$ & $0.19[0.12,0.25]$ \\
\hline ICILS 2018-Kazakhstan & & $0.08[0.01,0.14]$ \\
\hline ICILS 2018-Korea, Republic of & $\mapsto-1$ & $0.42[0.35,0.49]$ \\
\hline ICILS 2018-Luxembourg & $1=-1$ & $0.28[0.22,0.33]$ \\
\hline ICILS 2018-Portugal & $\mapsto$ & $0.15[0.09,0.22]$ \\
\hline ICILS 2018-Uruguay & -1 & $0.05[-0.03,0.13]$ \\
\hline ICILS 2018-Italy & $\mapsto-1$ & $0.19[0.11,0.26]$ \\
\hline ICILS 2018-Moscow (RUS) & -1 & $0.09[0.01,0.16]$ \\
\hline ICILS 2018-USA & $\mapsto-$ & $0.29[0.24,0.34]$ \\
\hline \multirow[t]{4}{*}{ RE Model } & $\sim$ & $0.21[0.15,0.27]$ \\
\hline & \begin{tabular}{l|l|l|l|l|} 
& 1 & 1 & 1
\end{tabular} & \\
\hline & $0.20 \quad 0.40$ & \\
\hline & \multicolumn{2}{|c|}{ Meta-analytic effect size (g) } \\
\hline
\end{tabular}

Note. The weighted average effect sizes were based on (two-level) random-effects (RE) models. 